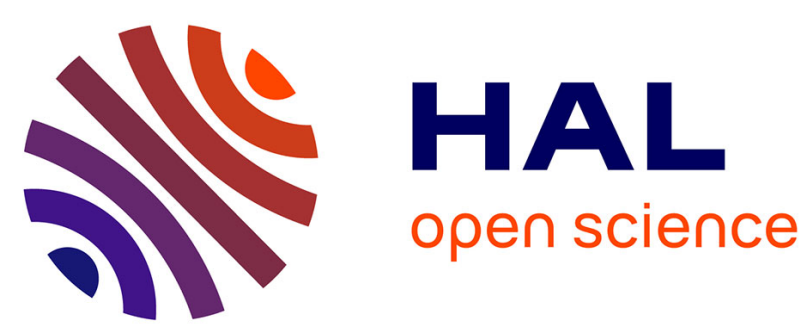

\title{
Physics on plasma chemistry
}

Pierre Fauchais, J. Rakowitz

\section{To cite this version:}

Pierre Fauchais, J. Rakowitz. Physics on plasma chemistry. Journal de Physique Colloques, 1979, 40

(C7), pp.C7-289-C7-312. 10.1051/jphyscol:19797444 . jpa-00219448

\section{HAL Id: jpa-00219448 https://hal.science/jpa-00219448}

Submitted on 1 Jan 1979

HAL is a multi-disciplinary open access archive for the deposit and dissemination of scientific research documents, whether they are published or not. The documents may come from teaching and research institutions in France or abroad, or from public or private research centers.
L'archive ouverte pluridisciplinaire HAL, est destinée au dépôt et à la diffusion de documents scientifiques de niveau recherche, publiés ou non, émanant des établissements d'enseignement et de recherche français ou étrangers, des laboratoires publics ou privés. 


\title{
Physics on plasma chemistry
}

\author{
P. Fauchais and J. Rakowitz
}

Laboratoire de Thermodynamique, U.E.R. des Sciences, Université de Limoges, 123, rue Albert-Thomas, 87100 Limoges

Résumé. - Dans cet article après un bref historique de la chimie des plasmas et une courte description des différents types de plasmas utilisés et de leurs moyens de production, nous présentons le réacteur de chimie des plasmas avec les différents problèmes rencontrés, notamment le mélange des réactifs, la trempe des produits et la catalyse. Nous continuons alors par une discussion sur les techniques de diagnostic utilisées en chimie des plasmas tant pour le plasma lui-même : mesure spectroscopique de la température et de la population des états excités, fluorescence laser, mesure de la vitesse des gaz et spectroscopie de masse des ions, que pour les matériaux en phases condensées introduits dans le plasma : vitesse, température de surface, population et diamètre des particules.

Pour les réactions en phase homogène un bref rappel des calculs à l'équilibre et de la cinétique des réactions est suivi par des exemples d'applications de tels calculs sur des expériences réelles : synthèse des oxydes d'azote dans un générateur à arc en courant continu, synthèse de l'acétylène et de l'acide cyanhydrique dans une torche haute fréquence, synthèse de composés organiques avec le métastable moléculaire de l'oxygène $\mathrm{O}_{2}{ }^{1} \Delta_{\mathrm{g}}$ produit dans une décharge $\mathrm{HF}$ à basse pression.

Pour les réactions en phase hétérogène, nous rappelons tout d'abord le calcul des propriétés thermodynamiques et de transport du plasma, puis nous considérons les problèmes de transfert de chaleur et de masse plasma-particules. Les applications illustrant ces calculs sont d'abord celles où le matériau traité subit dans le plasma uniquement un changement de structure physique : projection par plasma, sphéroidisation, vaporisation, condensation puis celles où il est le siège d'une transformation chimique.

\begin{abstract}
In this paper, after a brief historical review of plasma chemistry, a short description of the different types of plasmas used, and of their means of production, we will present the plasma chemistry reactor with the problems of mixing the reactants with the plasma, the quenching and the catalysis. This is followed by a discussion of diagnostic techniques either on the plasma itself : spectroscopic measurement of temperature and population, laser fluorescence spectroscopy, gas velocity measurements and mass spectroscopy of ions; or on the condensed materials injected into the plasma : velocity, surface temperature, population and diameters of the particles.

For the reactions in homogeneous phase a brief summary on equilibrium and kinetics calculations is followed by an illustration of the application of this calculations with three examples : NO synthesis in a DC plasma jet, $\mathrm{C}_{2} \mathrm{H}_{2}$ and $\mathrm{HCN}$ synthesis in a $\mathrm{HF}$ plasma torch, organic compound synthesis with the $\mathrm{O}_{2}{ }^{1} \Delta_{\mathrm{g}}$ metastable state produced in a HF low pressure plasma.

For the reactions in heterogeneous phase, first we recall thermodynamic and transport properties of the plasma and then we deal with heat and mass transfer plasma particles. The applications described are first concerned with physical changes of solid materials in plasma : plasma spraying, spheroidisation, vaporisation, condensation and second chemical reactions.
\end{abstract}

1. Introduction. - 1.1 Historical. - The first laboratory reaction of plasma chemistry was the synthesis of acetylene in 1797 by Henry and Dalton, although they were not aware of the fact that they were doing plasma chemistry with their capacitive discharge in methane. The first industrial plasma chemistry process was the synthesis of nitric oxide in an A.C. arc by Birkeland and Eyde [1] at the end of the nineteenth century. Unfortunately the empirical work done between 1880 and 1910 on chemical reactions in electric discharges was soon forgotten because the plasma was almost completely unknown and it was impossible to correlate any properties of the products obtained to the discharge.

Only a few decades ago, the number of studies in plasma chemistry increased considerably. The progress in the knowledge of plasmas allowed a better understanding of the role of the plasma components leading to a chemistry that takes into account not only neutral species and ions but also electrons, excited species (specially the metastables ones with a long life time often responsible of specific reactions) and also, if necessary, photons.

While numerous studies of elementary and simple reactions were developed under laboratory conditions with electric discharges, a large number of results is due to the research on the earth atmosphere chemistry, on the atmosphere of others planets and of the space. To illustrate this let us give some examples with the simplest molecules at $300 \mathrm{~K}$. 
a) $\mathrm{N} *\left({ }^{2} \mathrm{D}\right)$ (metastable) $+\mathrm{O}_{2} \rightarrow \mathrm{NO}+\mathrm{O}$

$$
\begin{aligned}
k & \sim 10^{-11} \mathrm{~cm}^{3} \text { molecule }{ }^{-1} \mathrm{~s}^{-1} \\
\mathrm{~N}\left({ }^{4} \mathrm{~S}\right) & \text { (fond) }+\mathrm{O}_{2} \rightarrow \mathrm{NO}+\mathrm{O} \\
k & \sim 10^{-16} \mathrm{~cm}^{3} \text { molecule }{ }^{-1} \mathrm{~s}^{-1},
\end{aligned}
$$

b) $\mathrm{O}^{*}\left({ }^{1} \mathrm{D}\right)$ (metastable) $+\mathrm{H}_{2} \rightarrow \mathrm{OH}+\mathrm{H}$

$$
\begin{gathered}
k \sim 3 \times 10^{-10} \mathrm{~cm}^{3} \text { molecule }{ }^{-1} \mathrm{~s}^{-1} \\
\mathrm{O}^{\circ}\left({ }^{3} \mathrm{P}\right) \text { (fond) }+\mathrm{H}_{2} \rightarrow \mathrm{OH}+\mathrm{H} \\
k \sim 1.5 \times 10^{-16} \mathrm{~cm}^{3} \text { molecule }{ }^{-1} \mathrm{~s}^{-1} .
\end{gathered}
$$

So the metastable states, even if their concentration is low must be taken into account as a distinct chemical specie.

In the seventies, with the improvement of measurement techniques, important progress have been made in the understanding of the phenomena and of the dynamics of chemical reactions in plasmas. The measurements show that, in almost all the cases, the plasmas used in plasma chemistry are out of equilibrium. Work in molecular physics allowed an understanding and modelisation of non equilibrium reactors defining the role of the kinetic, electronic, vibrational and rotational excitations and measuring the disequilibrium between these differents forms of excitation [2 to 5].

In this paper, after a short description of the plasmas used in plasma chemistry and of the means of production, we will recall the essential points of a plasma chemical reactor and the measurement techniques that can be used, either in homogeneous or in heterogeneous reactions. Then we will describe, through a few examples, how gaseous and heterogeneous reactions can be modeled mathematically with emphasis on what we know (or we believe to know) and what we would like to know better.

1.2 The Different TYPeS OF Plasma. - Many types of plasmas with different physical properties, usually produced by electrical discharge, have been described. Their state is characterized by the electron energy $\left(k T_{\mathrm{e}}\right)$ and electron density $\left(n_{\mathrm{e}}\right)$ figure 1 [6]. The plasmas used in plasma chemistry are high and low pressure arcs and glow discharges. In general, when the pressure is lowered the ratio $T_{\mathrm{e}} / T_{\mathrm{h}}$, the electron temperature to the heavy particles temperature, increases from about one at one atmosphere to about 100 for pressures under 1 torr. It is the same when one considers the intensity of the discharge current; more than $50 \mathrm{~A}$ for a ratio of about one (almost equilibrium) and less than $1 \mathrm{~A}$ for a ratio lower than 50. With high $T_{\mathrm{e}} / T_{\mathrm{h}}$, one has a high electron energy and a gas temperature near ambient. These plasmas are very well suited for the chemistry of materials sensitive to temperature effects (organic compounds for example), although electric power is

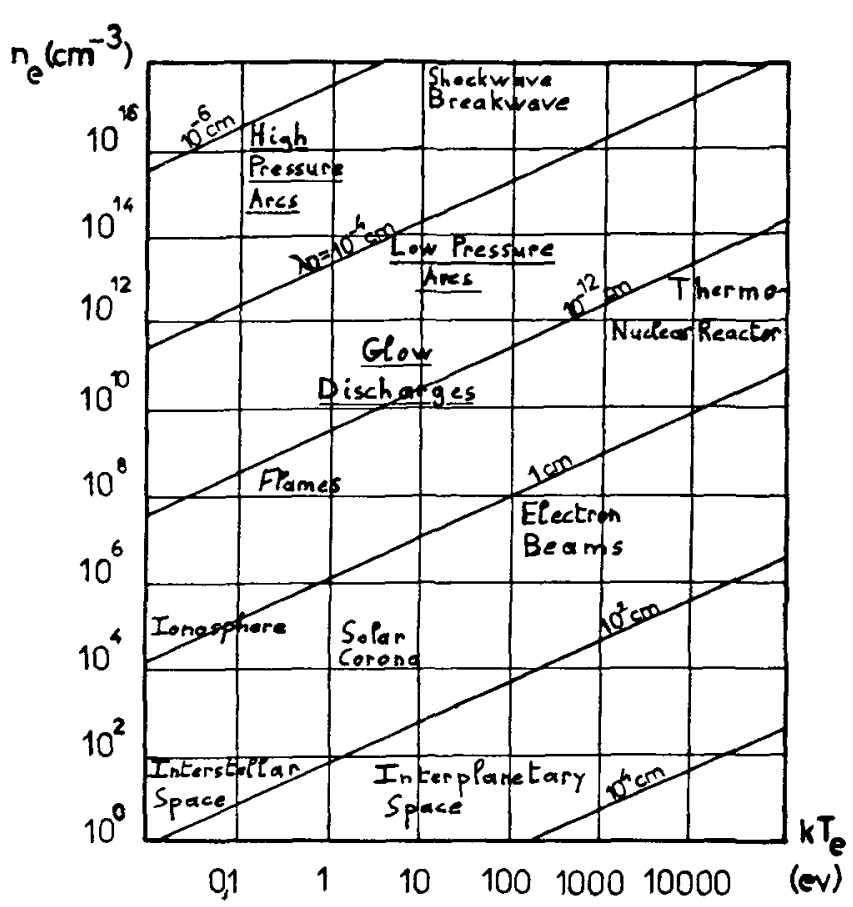

Fig. 1. - Typical plasma characterized by their electron energy and density (after [6]).

usually small and the mass treated is rather low (a few $\mathrm{mg} / \mathrm{s}$ ). On the contrary the plasmas near equilibrium have a rather high gas temperature (a few thousand $\mathrm{K}$ ) and they are well suited for reactions that needs high enthalpy transfer (fusion, spheroidisation, spraying, vaporisation) or for the synthesis of inorganic materials such as ceramics, small molecules (NO, $\mathrm{C}_{2} \mathrm{H}_{2}, \mathrm{HCN}, \ldots$ ). The electric power is high (up to $5 \mathrm{MW}$ ) and the mass treated important (a few $\mathrm{g} / \mathrm{s}$ to hundreds $\mathrm{g} / \mathrm{s}$ ). But often the temperature and density gradients are high along the radius of the plasma and it is difficult to get the same treatment for the products injected. Moreover in most cases one injects the cold reactants into the plasma jet after the electrodes and the resulting mixture is quite out of equilibrium $\left(T_{\mathrm{h}} \sim 1000-2000 \mathrm{~K}\right.$ and $T_{\mathrm{c}} \sim 5000-10000 \mathrm{~K}$ )

The plasmas mainly used in plasma chemistry are, in a stationnary situation, corona discharge, glow discharge, high frequency (HF) plasma torches, microwave (MW) discharges and arcs. The electrons are the principal vector of energy. Their mean energy $\bar{u}$ is such that the energy losses by elastic or inelastic collisions with the heavy particles, drift and diffusion to the walls or electrodes, balance the gain of energy due to the electric field. For positive column the gain frequency of charged particles is determined by the electric field $E / p(\mathrm{~V} / \mathrm{cm} /$ torr $)$ and the loss frequency by the reduced radius R.p [7]. With high fields $(E / p>50-100)$ the motion of electron is beam like, such is the case of the corona discharge. With medium $(1<E / p<100)$ electric field, the glow, HF and MW 
discharges at low pressure and low current are governed by the same energy loss of electrons (mainly inelastic collisions) as in corona discharge. On the contrary in discharges near equilibrium (high pressure $\mathrm{HF}$ and $\mathrm{MW}$ discharges and arcs) with a low electric field $(E / p<5)$ the energy loss of the electrons is due also to elastic collisions. It is then possible to define a critical value $E / p$ above which practically the total energy delivered by the generator is fed primarily into excitation, dissociation and ionisation.

In DC and AC plasma generators the electrons reach the anode and give rise to losses and to the creation of secondary species (pollution of the plasma). On the contrary with high frequencies, the polarity of the field is reversed in such a short time compared to the transit time of the electrons that only a very low percentage of them can reach the electrodes, in that case (HF and MW discharges) the electrodes can be disposed outside of the reactor and their is no pollution or catalysis with them.

We will not describe the glow discharge now well know [8] usually used at pressures under 100 torr and with powers less than $1 \mathrm{~kW}$.

The corona discharges usually with a power up to $1 \mathrm{~kW}$, a voltage up to $30 \mathrm{kV}$ and a frequency up to $500 \mathrm{kHz}$ is now used on industrial scale for ozone synthesis [9] and for the treatment of polyethylene films [10].

The microwave discharge allows excellent concentration of the electric field inside the cavity and, due to the low value of the wave length, the diameter of the plasma may be reduced to less than one centimeter. The electric field with a frequency $\omega$ penetrates the plasma for an electron density less than that corresponding to plasma resonance [11].

Therefore the frequencies usually used are in the range $200-3000 \mathrm{MHz}$, that plasma being produced with a resonant cavity [12]. Three years ago, a new method of microwave plasma generation was discovered and the production of long plasma columns was achieved by propagation of a surface wave [13]. For example working at $915 \mathrm{MHz}$ with argon at atmospheric pressure it is possible to achieve column length of $50 \mathrm{~cm}$ with power of $700 \mathrm{~W}$. The column diameter is about $1 \mathrm{~mm}$ and there is no LTE (electron density of $3 \times 10^{14} / \mathrm{cm}^{3}$ and excitation temperature about $3000 \mathrm{~K}$ ).

The HF torches (between 1 and $20 \mathrm{MHz}$ ) are the most widly used with pressures between 1 torr and 5 atmosphere. With a life time of $2300 \mathrm{hrs}$ an HF plasma device can work with a power up to $1 \mathrm{MW}$, with about $40-60 \%$ of the energy transfered to the plasma [14]. They can be used with agressive gases such as oxygen [14], chlorine [15] or $\mathrm{UF}_{6}$ [16]. The most often used technique of coupling is by induction. The minimum power necessary for self a sustained inductive discharge is determined by the gas nature, its pressure and the frequency of the electromagnetic field ; the cost of the source is reduced as the frequency is reduced from the $\mathrm{MHz}$ range to the hundreds of $\mathrm{kHz}$ range, unfortunately the minimum power increases from less than $10 \mathrm{~kW}$ to hundreds of $\mathrm{kW}$ unless the electrical conductivity is increased by the addition of an impurity $(\mathrm{K}, \mathrm{Cs}, \ldots)$ which is very polluting in plasma chemistry. Capacitive coupling leads to the formation of a phase shift between the electrodes and discharge current, thus reducing the efficiency of the discharge, but the minimum power for a self sustained discharge is lower than with induction coupling (for example [14] in the range $10-20 \mathrm{MHz}$, this minimum power is $0.2 \mathrm{~kW}$ for air and $1.0 \mathrm{~kW}$ for hydrogen operation).

$\mathrm{DC}$ or $\mathrm{AC}$ arcs are used mostly at atmospheric pressure when a high energy transfer is necessary (for example with solid reactants). The energy density is much higher than in $\mathrm{HF}$ torches at atmospheric pressure but the mean speed of the gas is very high (hundreds of $\mathrm{m} / \mathrm{s}$ ) so the residence time of the reactants is short. The first design of the torch was given in 1957 by Gage [17] : the arc is struck between a cathode rod and a nozzle anode. The forced gas flow extends the arc in the nozzle anode which is strongly cooled. Various torch configurations are possible depending upon stabilisation mode : tangential gas input in the arc channel (Fig. 2a), axial gas input along the cathode (Fig. 2b), segmented anode arc (Fig. 2c), magnetic rotation of the arc root, self induced by the arc current (more than $8000 \mathrm{~A}$ ) or externally generated (Figs. $2 d$ and $2 e$ ). The nozzle are generally made of copper, molybdenum or carbon and their life time is about $400 \mathrm{hrs}$ (erosion between $10^{-6}-10^{-7} \mathrm{~g} / \mathrm{C}$ ). The cathode

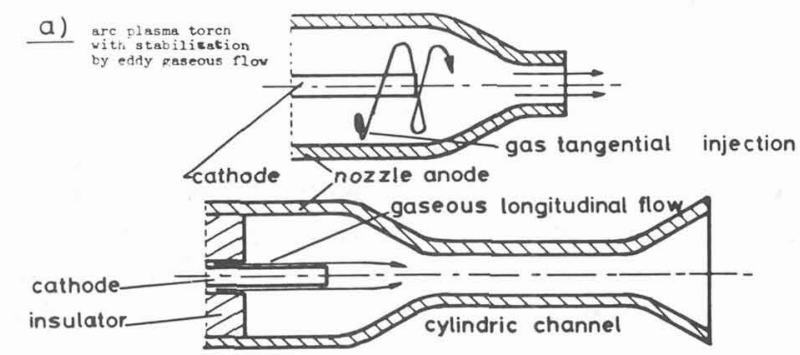

b) arc plasma torch with stabilination by longitudinal gaseous now

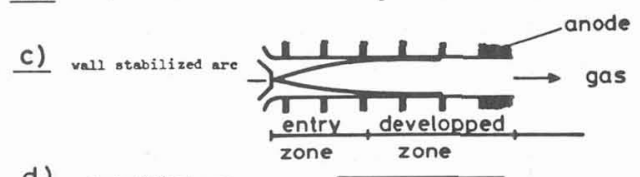

d) autostabilized arc

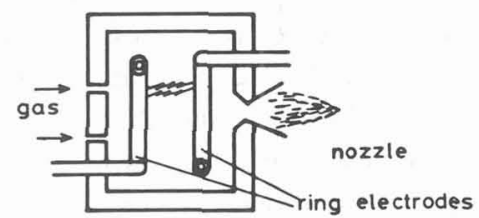

e) external stabilization

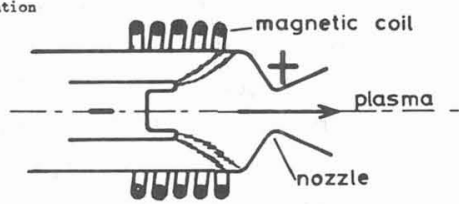

Fig. 2. - Principles of DC plasma torch stabilization. 
is usually of tungsten with thorium or carbon, the erosion of a W cathode is about $10^{-9}-10^{-10} \mathrm{~g} / \mathrm{C}$ with a life time of $150 \mathrm{hrs}$ approximately. Some metals like zirconium or hafnium may be used in presence of oxygen but their life time is less than $20 \mathrm{hrs}$. The thermal efficiency of such generators is up to $80 \%$ depending on the gas nature, its flow rate and of the arc intensity and voltage. Torches up to $5 \mathrm{MW}$ have been tested [18 to 34].

Some torches stabilized with liquids have been also developped, for example, the Lonza Corp [35] $250 \mathrm{~kW}$ torch stabilized by alcohol flow with a consumable carbon cathode.

When using $\mathrm{AC}$ current, in most cases the electrodes are made of copper, the arc striking between two tubes (Fig. 3) as in the design proposed by Fey [36] with power up to $1 \mathrm{MW}$. The arc rotates under the influence of a magnetic field and a tangential gas inlet. In order to avoid arc extinction a high frequency voltage is superimposed on the arc current $[37,38]$.

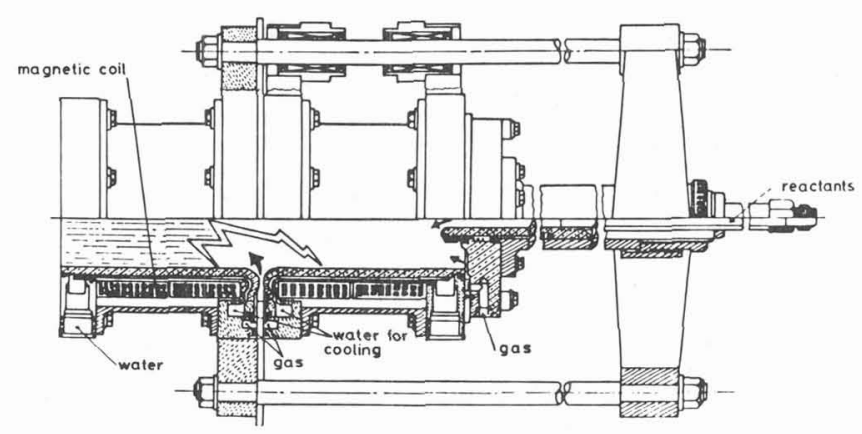

Fig. 3. - A 3,5 MW single-phase alternating-current plasma torch (after Fey [36]).

1.3 The plasma Chemistry reactor. - Generally [6] the experimental considerations in plasma chemistry may be divided into three parts (Fig. 4) corresponding as first approximation to the three stages of the reaction

- plasma generation,

- mixing of the reactants and reactions,

- quenching and recuperation of the formed products.

Unfortunately, plasma generation is not independent of the choice of the source and is of considerable importance for the others stages and the reactor must be conceived around the plasma source.

1.3.1 Mixing of the reactants with the plasma. As we can see is figure 4 the mixing can be done before or after the plasma generation. It is much more complicated to realize the mixing at high heavy particles temperature (because of the high viscosity of the plasma) but in all cases mixing inside the plasma, or just after the plasma generation, is a difficult technological problem and many studies have been carried out to determine the optimal injection mode

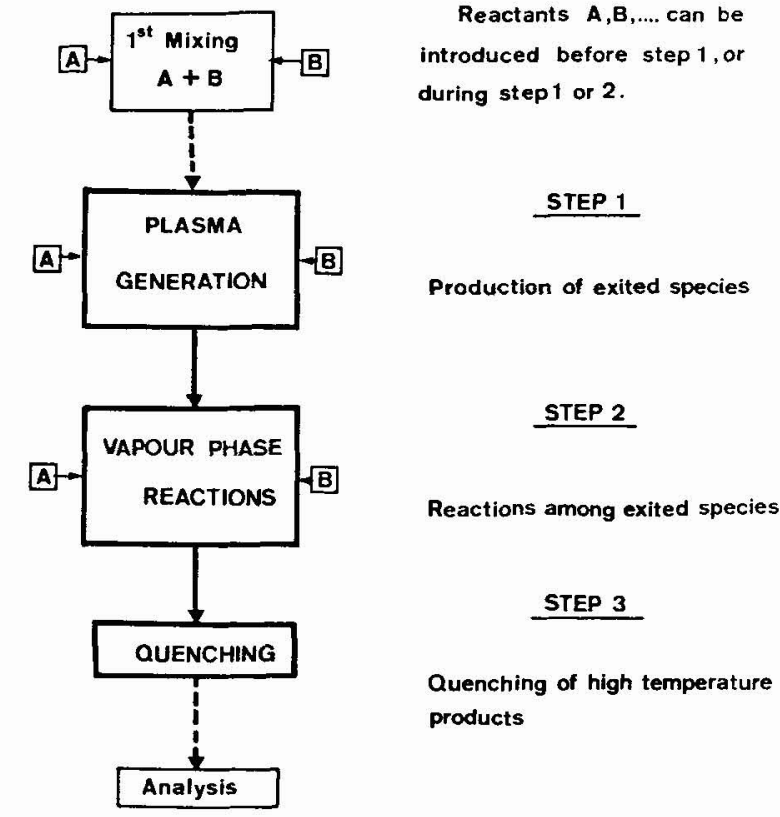

Fig. 4. - A plasma chemistry reaction.

[39 à 41]. Original systems have also been proposed such as hollow or porous cathodes [42], consumables cathodes and volatiles anodes $[43,44]$. Liquid injection may be realised with an ultrasonic atomizer [45] and solid particle injection is always a difficult problem.

1.3.1.1 Mixing before the generator. - In this case all the problems of mixing a cold gas with a plasma are solved but one has to be sure, as soon as the plasma is in contact with electrodes, that there is no reaction with them. For example a lot of precautions must be taken to use oxygen or chlorine in arcs. or to inject solid particles in the arcs using the Maecker effect [46].

Even if all the technical problems have been solved to inject the reactants before the plasma generation one has to think about the excitation of the reactants in the plasma because in this case there might be no selective excitation. For example if one injects oxygen and nitrogen into a HF plasma before the plasma generation the NO synthesis might be decreased because, in certain conditions the main processes are :

$$
\begin{aligned}
& \mathrm{N}+\mathrm{O}_{2}=\mathrm{NO}+\mathrm{O} \\
& \mathrm{O}+\mathrm{N}_{2}=\mathrm{NO}+\mathrm{N}
\end{aligned}
$$

and it is preferable to dissociate only $\mathrm{N}_{2}$ to get $\mathrm{N}$ and then to inject cold $\mathrm{O}_{2}$ after plasma generation.

A good example of selective plasma chemistry is the use of metastable levels to transfer their energy to the required excited states, for example excitation of $\mathrm{N}_{2}$ by $\mathrm{A}_{\mathrm{r}}^{\mathrm{m}}$ and then reaction with oxygen.

1.3.1.2 Mixing after plasma generation. - In this case there are no problems with electrodes but the 
injection of a cold reactant in an extinguishing plasma is often difficult, specially if it is a hot heavy particles plasma (near ETL) and this injection modifies strongly the plasma excitations and temperatures. One has to study the heat and mass transfer and the excitation transfer that often becomes the main reaction process.

1.3.2 Quenching. - Quenching in plasma chemistry plays two important roles :

- To withdraw excess energy from the excited new species which are formed.

- To prevent the inverse reactions that destroy the new products.

This is obtained by :

- excess energy removal, that is to say the reduction of the kinetic temperature that governs the creation-destruction equilibriums,

- the more or less specific destruction of the electronic and vibrational excited species (walls, collisions, recombinaisons) that can induce new reactions, some time undesirable. As well in hot as in cold plasma, in most cases of plasma chemistry, quenching is the most important phenomena determining whether a new product is obtained or not.

When the reaction takes place in a hot heavy particles plasma, the speed of quenching in its classical meaning is of first importance and the quenching techniques are characterized by the quenching speed usually between $10^{5}$ and $10^{8} \mathrm{~K} / \mathrm{s}$. The techniques used are : the fast expansion of the jet in a Laval nozzle [47] $\left(v=10^{7} \mathrm{~K} / \mathrm{s}\right)$, contact with cold walls [48 to 52] $\left(v=10^{7}\right.$ to $\left.10^{8} \mathrm{~K} / \mathrm{s}\right)$, liquid pulverisation [51 to 53 ], cold gas injection [54].

Of course the exact role of the quenching must be defined through the kinetics of the reactions if known but it is also important to emphasize that the moment of the quenching and the law of quenching $(\mathrm{d} T / \lambda T=f(T))$ is of primary importance for the results obtained. For example Polak [55] has shown that a delay $2 \times 10^{-3} \mathrm{~s}$ gives a reduction of the acetylene conversion from $15.5 \%$ to $10 \%$ and that a decrease of the quenching speed from $10^{8}$ to $10^{7} \mathrm{~K} / \mathrm{s}$ gives a reduction of the nitrogen conversion to NO from 9.6 to $6.4 \%$.

1.3.3 Catalysis. - Very few works have been devoted to catalysis in plasma. Some work has been done in homogeneous catalysis such as $\mathrm{O}_{2}$ dissociation with $\mathrm{N}_{2}$ and $\mathrm{NO}$ [52], $\mathrm{N}_{2}$ dissociation with $\mathrm{O}_{2}$ and $\mathrm{SF}_{6}$ [57] or with $\mathrm{HCl}$ [58] or with other gases [59]. Heterogeneous catalysis has been studied for the production of $\mathrm{C}_{2} \mathrm{H}_{2}$ and aniline in a plasma of $\mathrm{NH}_{3}-\mathrm{C}_{6} \mathrm{H}_{6}$ with $\mathrm{Ni}$ [60], propane craking in an argon plasma with $\mathrm{Fe}, \mathrm{NH}_{3}$ decomposition or $\mathrm{NO}$ synthesis with $\mathrm{Fe}, \mathrm{Ag}, \mathrm{Ca}, \mathrm{Pt}, \mathrm{Pd}$, Ni [61 to 67]. Unfortunately due to the complexity of the phenomena no real mechanism has been proposed. However in all cases the chemical rate of the reaction has been increased. For example Rapakoulias [68] has shown that, in a nitrogen $\mathrm{HF}$ plasma where $\mathrm{CH}_{4}$ is injected, catalysis with iron increases the conversion of $\mathrm{C}$ to $\mathrm{HCN}$ from $38 \%$ to $60 \%$ with a N/C ratio of 30 and Cavadias [69] has shown that with $\mathrm{WO}_{2}$ the conversion of Nitrogen to NO increases from 9 to $18 \%$ in a $\mathrm{N}_{2}-\mathrm{O}_{2} \mathrm{HF}$ plasma, with an induced energy of $80 \mathrm{kcal} /$ Nl. The problem is to understand what exactly happens, this results being obtained in one type of experiment and may be due to an improvement of the reactor performance in presence of metallic or oxides vapours.

1.4 Measurements IN Plasma CHEMISTRY. - - It is of prime importance to know the gas temperatures and gas velocities, the population of the excited states, the electron density and the temperatures and velocities of the condensed materials injected. Unfortunately these measurements, with the complex molecules encountered in plasma chemistry, are rather difficult from the experimental and theorical point of view, but the results, however approximate, are important to understand what happens during plasma treatment.

1.4.1 Plasma diagnostic. - 1.4.1.1 Spectroscopic diagnostic of temperatures and population of excited levels. - The degree of thermodynamic equilibrium has been extensively studied from a theoretical point of view by Griem [70] and Drawin [71], it has also been studied experimentally and compared with theory, for hydrogen, helium, and argon [72, 73] and recently for nitrogen [2]. The equilibrium conditions are generally stated from characteristic time and length for the process under consideration, compared to characteristic time and length of a plasma parameter. The following processes have to be studied:

- collision times between different particles $[74,75]$,

- Maxwellisation times [76],

- energy relaxations [77 to 81 ],

- kinetics of reactions [82],

- Boltzmann distribution relaxation [71],

- diffusion lengths [71, 82],

- equilibrium population of energy levels [71].

The characteristic parameters generally considered are the temperature and electron density which is of first importance under equilibrium conditions [83]. For example, with a DC plasma generator, two different zones have been pointed out in a nitrogen plasma jet at atmospheric pressure [82].

The first zone is such that $10^{15}<n_{\mathrm{e}}<10^{17} \mathrm{~cm}^{-3}$ and $9000 \mathrm{~K}<T<15000 \mathrm{~K}$, and the different criteria show that CLTE is realized. The second zone has a low electronic density $10^{12}<n_{\mathrm{e}}<10^{14} \mathrm{~cm}^{-3}$, and a quite low temperature $3000 \mathrm{~K}<T<7000 \mathrm{~K}$ and equilibrium is not realized, this is in part due to diffusion. Nevertheless in the two cases, the relaxation times of rotation-rotation, and rotation-translation 
exchanges are sufficiently low to consider the rotational and the translational temperatures to be equal.

For the spectroscopic diagnostic, one must note that :

- the lines must have a high intensity compared to the continuum,

- the lines must be well separated,

- at atmospheric pressure, an Abel's inversion [84] is generally needed.

The main diagnostics used are the following :

- The continuum emission due to free-free and free-bound radiation is well suited for temperatures between $8000 \mathrm{~K}$ and $14000 \mathrm{~K}$. The continuum intensity is proportional to $\mathrm{Ne}^{2} / \sqrt{T}$, it has been studied for nitrogen [85], argon [86], helium [86], hydrogen [87] and air [88].

- The ratio of two line intensities or the Boltzmann plot [84] gives an excitation temperature [2]. Figure 5 shows for example [2] a temperature chart of a nitrogen plasma jet. These measurements have been performed spectroscopically with an automatic data acquisition system connected to a computer, which reduced the measurements time of the excitation temperature to a few hours including Abel's inversion.

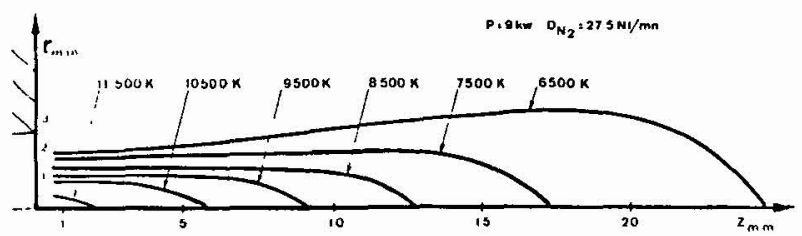

Fig. 5. - Temperature contours in a DC nitrogen plasma jet [2]

- When purely Stark, the atomic line profiles are well suited for the measurement of electron density (usually one uses Stark width of hydrogen or helium lines with either gases introduced in low quantity (less than $0.5 \%$ ) in the plasma gas) [70].

- When purely Doppler, the atomic line profile gives the neutral kinetic temperature.

- When the line profile is due to both contributions, Stark and Doppler, the respective broadening must be separated, and one needs a high resolution apparatus. The most often studied profiles are those of argon [89], helium [90] and nitrogen [2].

- When the excitation temperature is known, absolute intensity of lines can be used to measure the upper level population of the transition considered.

- When the lines are sufficiently separated molecular band spectra are used to measure the rotational temperature (equal to the translational one). But even when the lines are not separated, comparison between the experimental profile and a set of calculated profiles versus temperature give rather good information especially below $6000 \mathrm{~K}[84,2,91]$. This method is rather usefull for the measurement with complex spectra due to the emission of different molecular bands that overlap as for example in mixtures of $\mathrm{N}_{2}-\mathrm{O}_{2}$ or $\mathrm{SiCl}_{4}-\mathrm{N}_{2}$ or $\mathrm{H}_{2}$ as used in plasma chemistry. For example [91], figure 6 shows the calculated NO $(\gamma$ band $0-2$ and 1-3) at $5000 \mathrm{~K}$ and the experimental corresponding spectra.

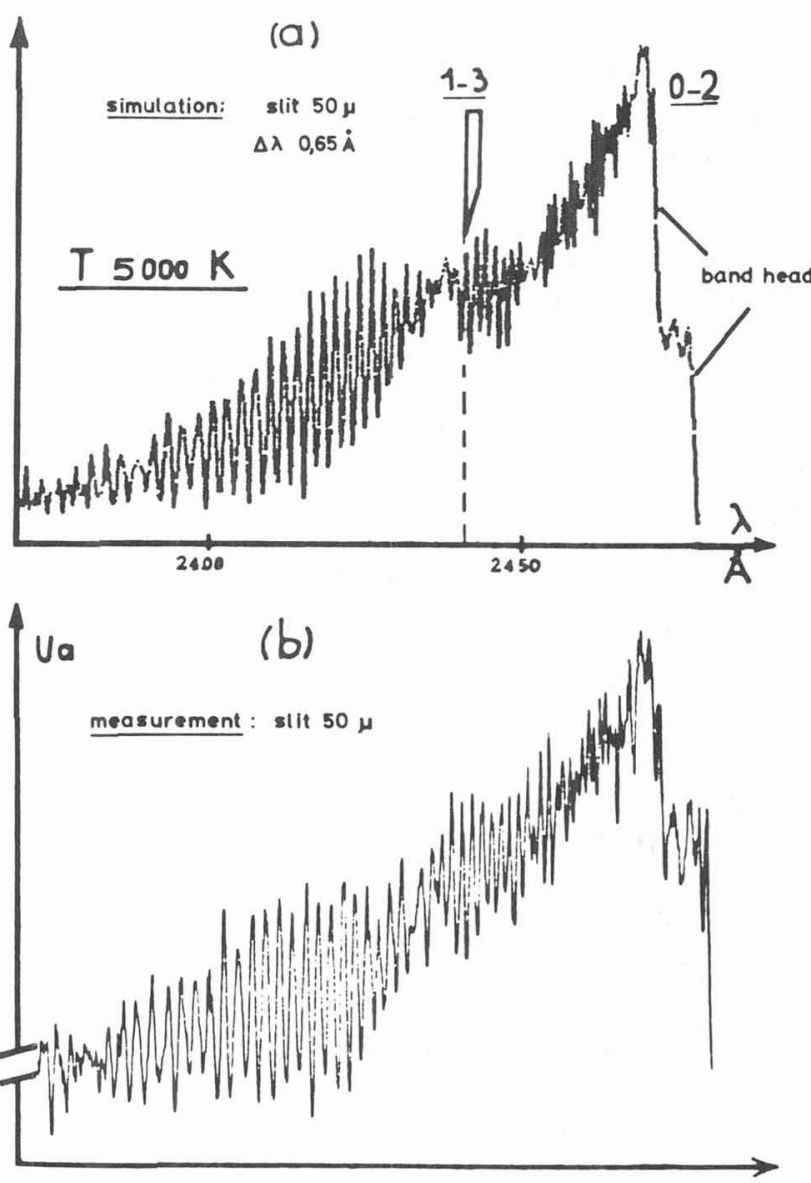

Fig. 6. - NO $(\gamma 0-2$ and $\gamma 0-3)$ bands with a mean resolution (after [91]).

1.4.1.2 Laser fluorescence spectroscopy. - The development of tunable lasers with the possibility of doubling the frequency provides new possibilities to determine particle densities for a given atomic or molecular specie (in ground or excited states) or to study liquid droplets or micrometric powders.

In the last two cases, photon elastic scattering is used in Mie Scattering $\left(\sigma \sim 10^{-10} \mathrm{~cm}^{2}\right)$ while in the first, one uses Rayleigh $\left(\sigma \sim 10^{-28} \mathrm{~cm}^{2} \sim \lambda^{-4}\right)$ and resonant scattering $\left(\sigma \sim 10^{-12} \mathrm{~cm}^{2}, 10^{-17} \mathrm{~cm}^{2}\right.$ for atoms and molecules respectively). Fluorescence study is also used $\left(\sigma \sim 10^{-18} \mathrm{~cm}^{2}\right)$ and Raman scattering $\left(10^{-25} \mathrm{~cm}^{2}>\sigma>10^{-29} \mathrm{~cm}^{2}\right)$. Most of the measurements performed in plasma chemistry use fluorescence. The main problem is then to get sufficiently high laser intensity to achieve saturation 
and to get a fluorescence signal independent of the laser intensity and only proportional to the density of the particle in the lower state. For example a calculation made in the laboratory shows that for a laser pulse tuned to a rotational line of an electronic transition of the $\mathrm{NO}(\gamma)$ band the energy density must be greater than $2.5 \mathrm{~J} / \mathrm{m}^{2}$. But even if the pulse energy density is not sufficient to get saturation some models have been proposed to calculate the non saturation case, for example, with atomic lines [7]. In all the cases this method requires a fast electronic, due to the desexcitation time of the excited states (a few nanosecond). As it is necessary to focus the laser beam in a few hundredth of microns volume, it is possible, when observing at $90^{\circ}$ of the laser beam, to avoid the Abel inversion to measure the local concentrations. This method is now one of the most promising one to get information on the chemical reactions between excited states and physicist began to study the kinetic constants in simple gases like nitrogen [92], helium $[93,94]$, argon [95] and hydrogen [96, 97].

1.4.1.3 Plasma gas velocity measurements. Under the assumption of LTCE a rather simple method consist in measuring the dynamic pressure of the gas with a probe. But, in that case, the probe disturbs the plasma flow, so that it must be precisely profiled [98, 99]. Figure 7 shows the velocity distribution of an $\mathrm{Ar}-\mathrm{H}_{2}$ DC plasma jet [100].

- Another technique consists of the observation of a small electrical perturbation superimposed on the discharge [101, 102]. The use of a pulsed laser now offers new opportunities for this type of measurement.

- A third technique uses very small particles injected into the plasma. The particles velocity, supposed to be the same as that of the gas, ean by measured by laser anemometry in HF or DC plasmas $[103,104,105]$.

- Finally for very high velocities (higher than $2000 \mathrm{~m} / \mathrm{s}$ ) it is possible to utilize the Doppler shift of the lines [106].

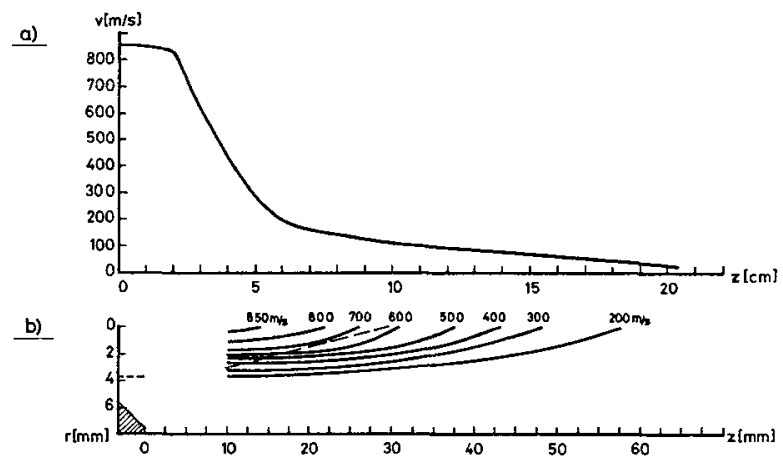

Fig. 7. - Velocity distribution in a DC plasma-jet (after [100]).

1.4.1.4 Mass spectroscopy of ions. - For low pressure plasma, by a small extraction aperture or wall probe, ions are extracted from plasma and by two additional apertures are led to the mass-spectrometer, where an additional grid may allow an energy analysis. With such a device, used essentially for low pressure plasma, neutral as well as positive or negative ions can be analyzed by measuring current densities and energy. The main problem is the interpretation of the results because in front of the probe a sheath in formed, which changes the properties of the particles coming from the plasma to the probe. A lot of studies have been devoted to this problem and, for example, one can find a detailed analysis in [107].

1.4.2 Condensed particles injected into the plasma. - 1.4.2.1 Velocity of condensed particles. - There are three kinds of measurement methods:

- Mechanical methods, the flow of particles is momentarily stopped with a barrier, and then one observes the rate of the flow of particles downstream. With this technique a mean velocity is obtained in a plane orthogonal to the flow direction. With two holes, in two discs it is possible to obtain more refined measurements. With this type of technique it is possible to measure velocities between 50 and $200 \mathrm{~m} / \mathrm{s}$ [108].

- Optical methods have been, up to day, the most often used. An image of the jets is photographically recorded either with a rotating miror $[100,109]$, or an ultra rapid camera [110]. Velocities up to $750 \mathrm{~m} / \mathrm{s}$ have been measured by this technique.

- The so-called opto-electronic methods use optical detection of the particles connected to an electronic system for data treatment. This if for example the case of the plasmacope developped by Gold [111]; the plasmacope makes an analysis in space and time of the luminous perturbation of particles flowing in the plasma. A more sophisticated method is now available : Laser Döppler anemometry $[112,113]$. Many techniques of this type have been developed and give fairly good results. The velocity of particles can be measured at any point in the plasma [114 to 119]. For example figure 8 from [104]

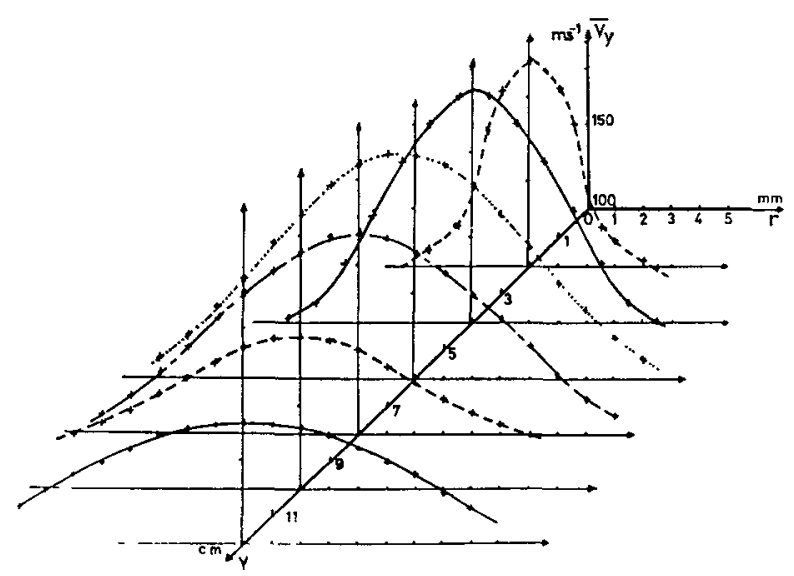

Fig. 8. - Radial particle velocity distribution along jet axis (after [104]). 
shows the axial and radial velocity of alumina particles injected in a nitrogen-hydrogen plasma.

1.4.2.2 Temperature of condensed particles.

The analysis of the radiation emitted from the surface of the particles gives the radiation temperature. This method has been used by Bonet; a monochromatic photograph of the moving particles is recorded through a pyrometer which gives the reference radiation [120].

- Lesinski [121] has developed a similar method by using a photomultiplier in place of camera, the reference radiation is given by a hole travelling very rapidly in front of a reference tungsten ribbon lamp. This method has been refined by Vardelle [104], who has made a statistical treatment of the received signals. The main difficulties with this system is to know exactly the particle diameters, and their emissivities. Figure 9 shows the temperature of alumina particles along the axis of a nitrogen hydrogen plasma jet.

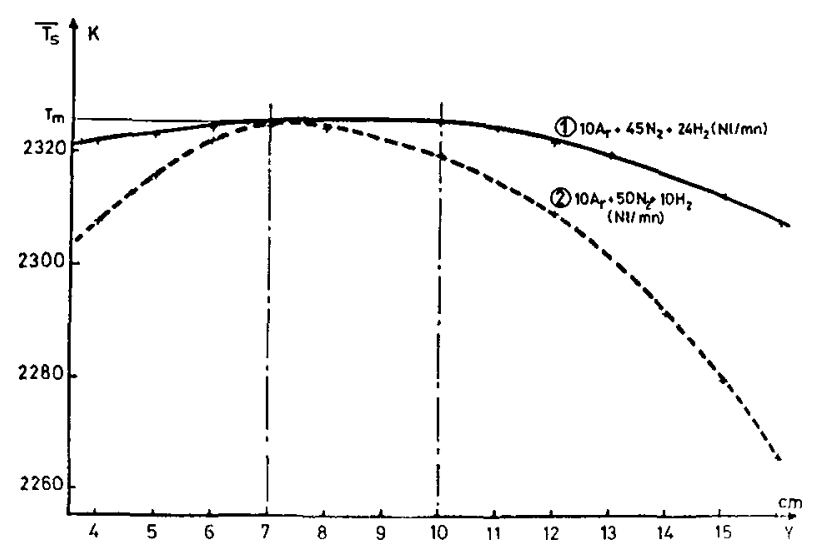

Fig. 9. - Particle temperature distribution along jet axis (after [104]).

1.4.2.3 Population and diameter of the particles. - The population of the particles in a plasma may be measured very simply counting, during a given time, the pulses resulting of the light scattered by the particles passing through a laser beam ( $\mathrm{Ar}^{+}$laser). Using a laser beam of $100 \mu \mathrm{m}$ diameter and detecting

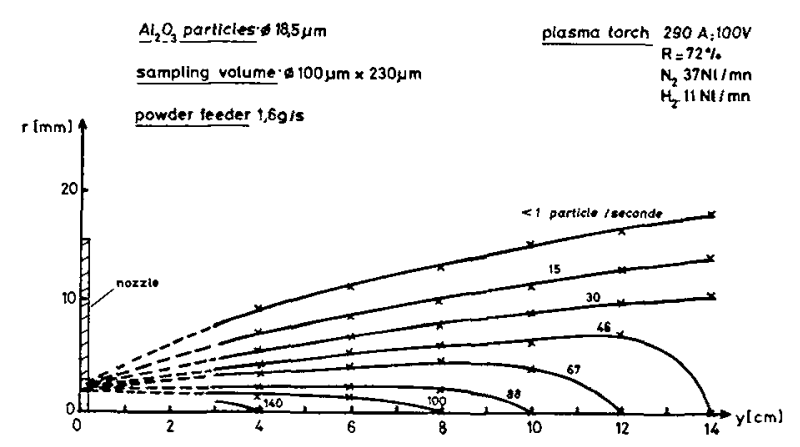

Fig. 10. - Particles $(d=18.5 \mu \mathrm{m})$ isoflow curves (after [104]). the scattered light at $90^{\circ}$ with a diaphragm of $100 \mu \mathrm{m}$ a ponctual measurement can be achieved and for example figure 10 shows the distribution of alumina particles injected in a nitrogen DC plasma jet.

- The diameter of the particles (very important for the temperature measurement) may be measured also through the scattered laser radiation. For example, Penner [122] gives the conditions to be filled, and the theoretical curves needed, to define lognormal particle-size distributions from measured half widths and detectabilities of scattered laser power spectra.

2. Plasma chemical reaction in homogeneous phase. - In this case the plasma may be considered some times as in equilibrium, but in any case the quenching of the products is always out of equilibrium.

2.1 Equilibrium CALCUlations. - Under ideal conditions of thermodynamic equilibrium it is possible to determine the products resulting from a given treatment but the problem is to know to which extent calculations assuming this equilibrium are applicable to real systems. For that the chemical reaction must proceed more rapidly than the physical phenomena such as relaxation of energy levels or maxwellisation. For example with a very simple calculation one can say that on the axis of a DC plasma jet the temperature varies by $1 \%$ in $2.5 \times 10^{-5} \mathrm{~m}$, so that at $250 \mathrm{~m} / \mathrm{s}$ a variation of temperature of $1 \%$ corresponds to $10^{-7} \mathrm{~s}$, so in order that thermodynamic equilibrium can be applied the reactions times must be less than $10^{-7} \mathrm{~s}$. The ratio of this chemical reaction time $t_{\mathrm{c}}$ to the mechanical residence time $t_{\mathrm{m}}$ is the Damköhler parameter [123] $D_{\mathrm{i}}\left(D_{\mathrm{i}}=t_{\mathrm{c}} / t_{\mathrm{m}}\right)$ and the equilibrium is obtained for $D_{\mathrm{i}} \ll 1$. This kind of reactions times may be encountered if the temperature is greater than $5000 \mathrm{~K}$ but in all the cases during quenching equilibrium is not possible.

The thermodynamic calculation consists in finding the chemical composition which gives the minimum Gibbs free energy [124] under the contraints of the law of conservation of matter and electrical neutrality. One gets a system of non linear equations that must be solved by use of numerical methods by computer $[125,126]$. The data are sometimes limited to $6000 \mathrm{~K}$ and it is necessary to carry out calculations of partition functions from spectroscopic data [127].

The results obtained must be considered very carefully but usually they give some qualitative indications about what happens. For example [91], if one consider a mixture of $\mathrm{N}_{2}-\mathrm{O}_{2}$ at equilibrium at atmospheric pressure, figure 11 , the maximum of $\mathrm{NO}$ one could obtain is $6.5 \%$ at $3500 \mathrm{~K}$, but as we will see, it is possible as a function of the quenching techniques to get less or more. The calculations [128] of the system $\mathrm{SiO}_{2}-\mathrm{C}$ shows (Fig. 12) the existence of a threshold temperature in the range $2500-3000 \mathrm{~K}$. 


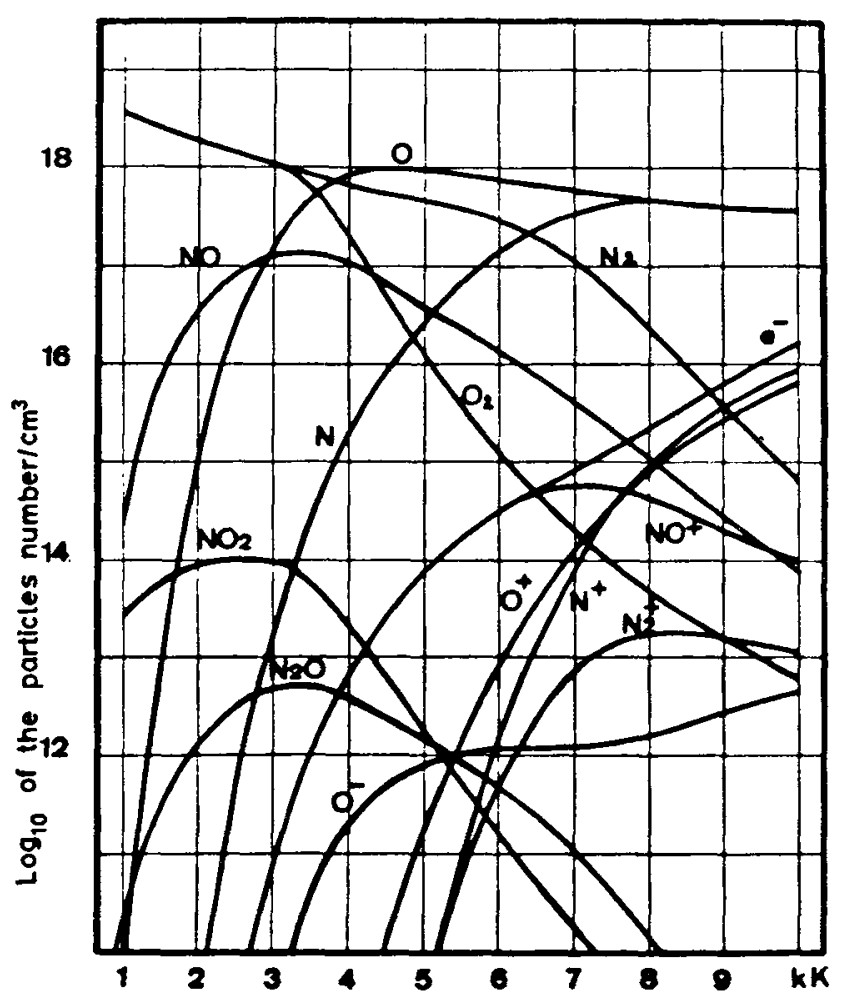

Fig. 11. - Composition of an $\mathrm{N}_{2} \mathrm{O}_{2}$ plasma at $1 \mathrm{~atm}(\mathrm{~N} / \mathrm{O}=1)$ (after [91]).

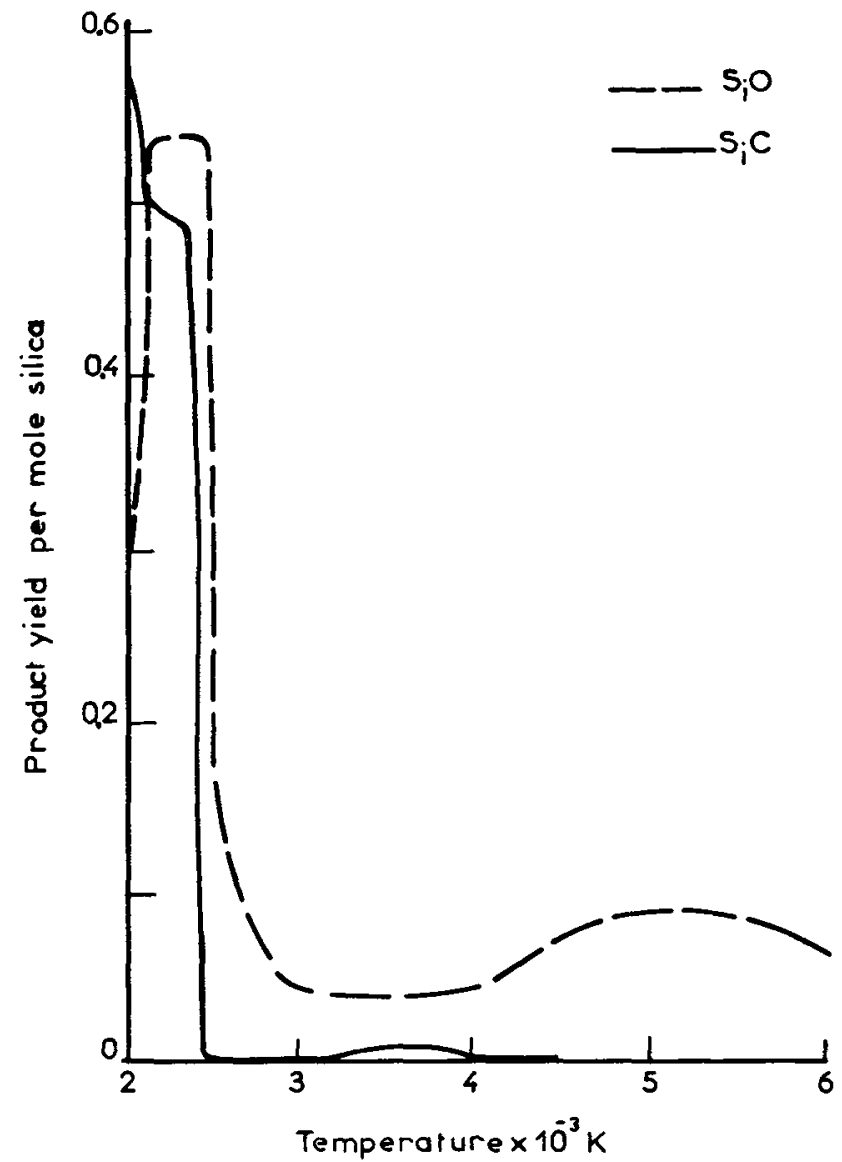

Fig. 12. - Production of $\mathrm{SiO}$ and $\mathrm{SiC}$ (at 2.0 moles of carbon) (after [128]).
On one side of this temperature the only species are $\mathrm{SiO}_{2}, \mathrm{SiO}$ and $\mathrm{SiC}$, while there is always a low concentration of $\mathrm{SiO}$ above that temperature. Unfortunately thermodynamic cannot describe what happens during the cooling phase that becomes the most important to get pure $\mathrm{Si}$.

2.2 Kinetics CALCULATIONS. - The kinetics models tend to predict the influence of physical conditions on the reaction rates specially when $D_{\mathrm{i}} \simeq 1$. In a stationnary medium, the variation by unit time of the ith specie concentration $C_{\mathrm{i}}$ is given [129] by :

$$
\frac{\partial x_{\mathrm{i}}}{\partial t}=\nabla \cdot\left(D \nabla C_{1}\right)+P_{\mathrm{i}}-S_{\mathrm{i}}
$$

where $D$ is the diffusion coefficient, $S_{1}$ the source term and $P_{\mathrm{i}}$ the losses term.

\subsubsection{Chemical reactions at high temperature. -} Disregarding the diffusion process because its contribution introduces many difficulties in the solution of (1) and because often the data are not well known $[130,131]$, considering a mixture of I chemical species $A_{i}$ reacting in $J$ chemical reaction with reactions rate constants $k_{j}$ :

$$
\sum_{j=1}^{\mathrm{J}} v_{j i} \mathrm{~A}_{i} \stackrel{k_{j}}{\rightarrow} \sum_{j=1}^{\mathrm{I}} v_{j i}^{\prime} \mathrm{A}_{i}
$$

and assuming the thermodynamic temperature of the system is assigned to follow a law, $T=f(t)$, at constant pressure, the time dependance of the chemical composition of the system is calculated by solving the following differential system

$$
\frac{\mathrm{d} c_{i}}{\mathrm{~d} t}=w_{i}-\left(\frac{c_{l}}{\rho} \sum_{i=1}^{\mathrm{I}} w_{i}+\frac{c_{i}}{T} \frac{\mathrm{d} T}{\mathrm{~d} t}\right)
$$

with

$$
w_{i}=\sum_{j=1}^{\mathrm{J}} k_{j}\left(v_{j i}^{\prime}-v_{j i}\right) \prod_{l=1}^{\mathrm{I}} y_{l}^{v^{\prime l}} \quad \text { and } \quad \rho=\frac{p}{k T} .
$$

The solution is generally obtained by numerical integration methods, which must be highly stable one, as the problems encountered are locally exponential giving rise to the phenomenon called stiffness. Warner [130] gives a critical review of the different methods that can be used. However the main problem is due to a poor knowledge of the specific reaction rates $k_{j}$. This quantities are strongly temperature dependent and as the Arrhenius law is not sufficient in plasmas one has to take into account the potential energy of each reaction. But each chemical reaction usually consists of a set of elementary steps involving a group of molecules or atoms which gives the final reaction products after rearrangement. During an elementary step, the evolution of the system may be described by the trajectory of a representative point moving on the potential surface. In the general case the system moving on the surface must jump over a 
potential barrier the height of which is equal to the activation energy $E_{\mathrm{a}}$. The system configuration in the neighbourhood of the top of this barrier being called the activated complex. Unfortunately solving the quantum mechanical equations to get the potential surface configuration is very difficult [131 to 133].

In this case it is possible to write

$$
k(T)=P \cdot Z_{0} \cdot \exp \left(-E_{\mathrm{a}} / k T\right)
$$

where $Z_{0}$ is calculated through the collisional cross section (typical values are $10^{-16} \mathrm{~cm}^{3}$ part $^{-1} \mathrm{~s}^{-1}$ for two bodies collisions and $10^{-32} \mathrm{~cm}^{6}$ part $^{-1} \mathrm{~s}^{-1}$ for three bodies collisions), and $P$ a steric factor involving the entropy variation occuring in the reaction [131 to 133] and calculated with the activated complex theory.

Finally the most difficult problem to solve is not to calculate a numerical coefficient for a given temperature, but to know what modifications of the model must be done for a very rapid and important variation of the species temperature.

2.2.2 Chemical reactions in low temperature plasma. - In this case (low pressure plasma) one neglects the temperature variation and the processes taken into account $[134,135]$ are the collisions process (mainly through the electrons and the metastables states) for ionisation, recombination, excitation and desexcitation and spontaneous radiative transitions and radiative recombination. The system of eq. (1) must then be solved with some additional condition about the evolution of the electron population (generally imposed by the experimental conditions). As in the preceeding case the problem is the determination of $k_{j}$. One also has to take care when neglecting the terms corresponding to small values of $k$ (see the characteristics values of $Z_{0}$ in the preceeding section) that in the equation it is the product of the population by $k$ that is involved.

2.3 EXAMPLE : NO SYNTHESIS IN A DC PLASMA JET. -- As shown by the numerous papers presented at the last Symposium on plasma chemistry the NO synthesis in plasma is a research field actuality. In Limoges we have studied this synthesis with a DC plasma jet (up to $30 \mathrm{~kW}$ ) [91]. The plasma gasmixture of $\mathrm{N}_{2}$ and $\mathrm{O}_{2}$ is introduced along the cathode and cold oxygen is injected downstream the arc into the nozzle and thus contributes to the quenching which is completely achieved by removing the gaseous products through a water cooled probe. This device works with powers between 5 and $27 \mathrm{~kW}$ corresponding to specific enthalpy between 1.4 and $7.7 \mathrm{kWh} / \mathrm{kg}$ and the gas flow velocity at the nozzle exit measured without oxygen injection is between 500 and $1000 \mathrm{~m} / \mathrm{s}$.

The experimental results $[136,137]$ have pointed out at atmospheric pressure that :

- energetic consumption is minimal with an $\mathrm{N}_{2}$ initial molar fraction of $50 \%$,
- nozzle must be long enough to prevent the arc root ta stay downstream the cold oxygen injection,

- cold wall quenching device allows to increase NO molar fraction and to reduce energetic consumption,

- the best results are obtained with a plasma of pure nitrogen with $25 \mathrm{kWh} / \mathrm{kg}$ of $\mathrm{NO}$ and a nitrogen conversion to NO of $9 \%$.

To explain such results (the equilibrium conditions gives a maximum of $6.5 \%$ at $3500 \mathrm{~K}$ ) one has considered the following reactions for $T<5000 \mathrm{~K}$

$$
\begin{aligned}
& \mathrm{O}_{2}+\mathrm{M}=\mathrm{O}+\mathrm{O}+\mathrm{M} \\
& \mathrm{N}_{2}+\mathrm{M}=\mathrm{N}+\mathrm{N}+\mathrm{M} \\
& \mathrm{NO}+\mathrm{M}=\mathrm{N}+\mathrm{O}+\mathrm{M} \\
& \mathrm{O}_{2}+\mathrm{N}_{2}=\mathrm{NO}+\mathrm{NO} \\
& \mathrm{O}+\mathrm{N}_{2}=\mathrm{NO}+\mathrm{N} \\
& \mathrm{N}+\mathrm{O}_{2}=\mathrm{NO}+\mathrm{O}
\end{aligned}
$$

with the kinetics constants gathered by Prud'hommes [138] and these recommended by Baulch [139]. The temperature evolution of the gas in the plasma has been determined by assuming a mean enthalpy temperature (homogeneous temperature in the nozzle) varying with a parabolic law for heating and quenching as represented on figure 13. At the beginning [137], as one can see on figure 14, the reaction (4) is responsible of the NO production and the NO production rate is maximum between 8 and $12 \mathrm{~s}$. This simplified model gives a rather good agreement with the experimental results and it has emphasized the importance of the heating rate, which as far as we

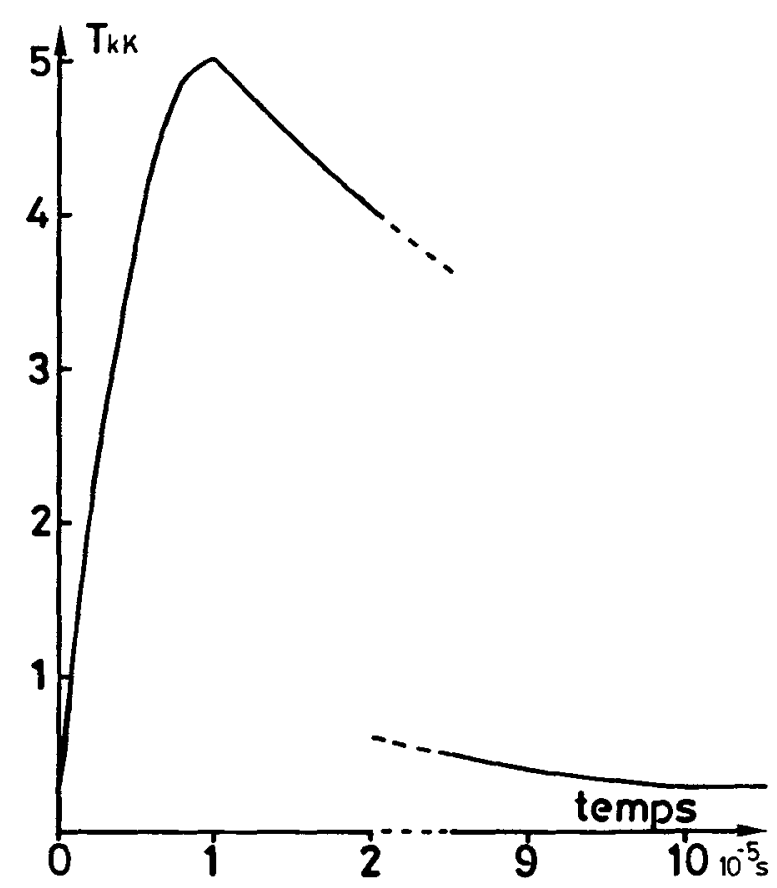

Fig. 13. - Evolution of the temperature as a function of time (after [136]). 


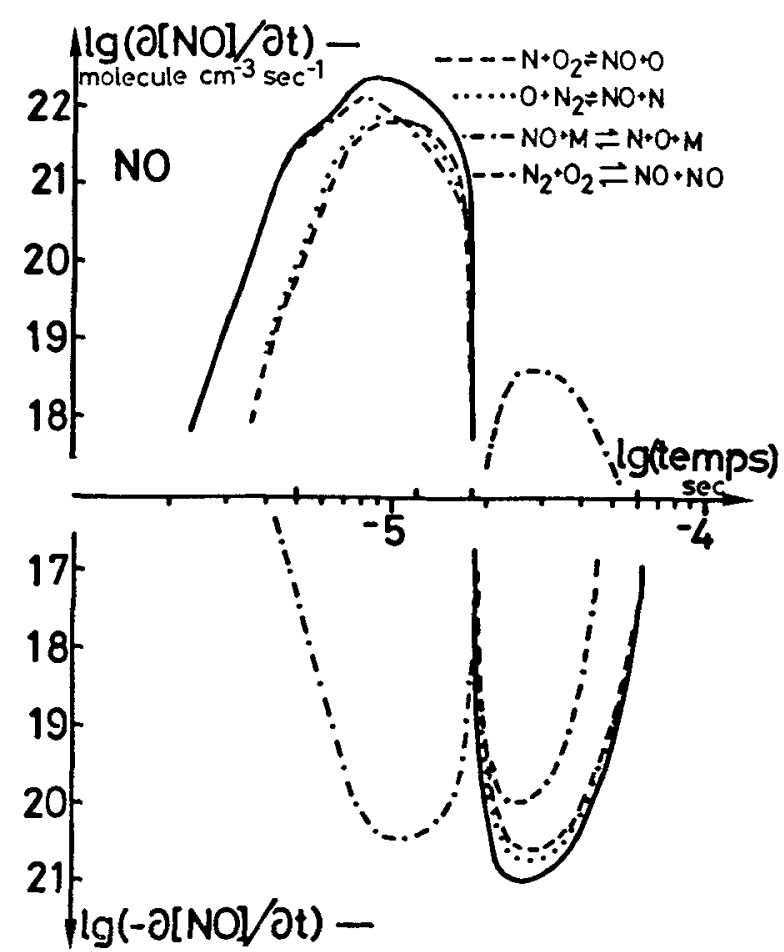

Fig. 14. - Evolution of the NO rate production as a function of time (after [136]).

know, have never been mentioned before, and also the necessity to have a high quenching rate $\left(10^{8} \mathrm{~K} / \mathrm{s}\right.$ at the beginning).

2.4 EXAMPLE : $\mathrm{HCN}$ AND $\mathrm{C}_{2} \mathrm{H}_{2}$ SYNTHESIS IN A HF LOW PRESSURE PLASMA. - The nitrogen plasma is created by HF inductive coupling inside a glass tube of $100 \mathrm{~mm}$ diameter [68] with a gas flow rate between 0.5 and $2.5 \mathrm{Nl} / \mathrm{mn}$. The pressure is varied between 5 and 40 torrs with a power of about $2.5 \mathrm{~kW}$. Cold methane is injected counter-current in the extinction plasma. In such a plasma the main mechanism is the excitation of the heavy particles by collisions with the electrons and the nitrogen plasma, studied by emission spectroscopy $\left(1^{-}\right.$of $\mathrm{N}_{2}^{+}, 1^{+}$and $2^{+}$of $\mathrm{N}_{2}$ ), is such that $T_{\mathrm{e}} \sim 25000 \mathrm{~K} \gg T_{\mathrm{v}}(\sim 5500 \mathrm{~K})>T_{\mathrm{r}} \sim T_{\mathrm{tr}}$ $(\sim 1700 \mathrm{~K})$. When the pressure is increased the rotational temperature $T_{\mathrm{r}}$ increases and the electronic $T_{\mathrm{e}}$ and vibrational $T_{\mathrm{v}}$ temperatures decreases.

With $\mathrm{N}_{2}$ and $\mathrm{CH}_{4}$ two exchange reactions are possible :

Fixation reaction

$$
\mathrm{N}_{2}+2 \mathrm{CH}_{4} \rightarrow \mathrm{HCN}+2 \mathrm{H}_{2} \text {. }
$$

Transfer reaction

$$
\mathrm{N}_{2}+2 \mathrm{CH}_{4} \rightarrow \mathrm{C}_{2} \mathrm{H}_{2}+3 \mathrm{H}_{2}+\mathrm{N}_{2} \text {. }
$$

Due to the energy requirements (neglecting the atoms because the emissions lines are very weak), the fixation reaction is postulated [68] to be more probable with the $\mathrm{C}^{3} \Pi$ and $\mathrm{B}^{3} \Pi$ states and the transfer

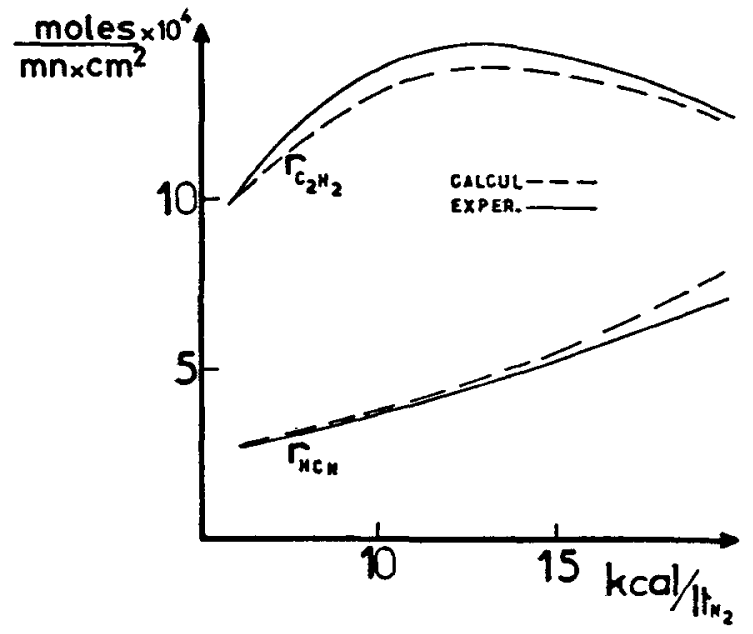

Fig. 15. - Evolution of the formation rate of $\mathrm{C}_{2} \mathrm{H}_{2}$ and $\mathrm{HCN}$ versus induced energy (after [68]).

reaction with $\mathrm{A}^{3} \Sigma$ (metastable state). We have to mention that this hypothesis neglecting the atoms and specially the $\mathrm{N}^{2} \mathrm{D}$ metastable state might be over simplified specially when one reminds that the dissociation of the $\mathrm{C}^{3} \Pi_{\mathrm{u}}$ state gives $\mathrm{N}^{2} \mathrm{D}$ and $\mathrm{N}^{4} \mathrm{~S}$. For a given N/C ratio the experimental results show an increase of $\mathrm{HCN}$ conversion and an increase followed by a decrease of $\mathrm{C}_{2} \mathrm{H}_{2}$ with the increase of the specific energy and an increase of the nitrogen flow rate. $\mathrm{C}_{2} \mathrm{H}_{2}$ conversion decreases and $\mathrm{HCN}$ increases with the increase of the pressure. To explain this results a simplified kinetic model (with no temperature evolution) has been proposed [68] postulating that the fixation rate is much greater than the transfer reaction rate and that the density of $\mathrm{A}^{3} \Sigma$ states is greater than the density of $\mathrm{C}^{3} \Pi$ states. Figure 15 shows a comparison of the evolution with the specific energy of the measured and calculated formation rates of $\mathrm{C}_{2} \mathrm{H}_{2}$ and $\mathrm{HCN}$. When the influence of the pressure is considered the results are in good agreement with Polanyi's theories [140]. The energy diagram of

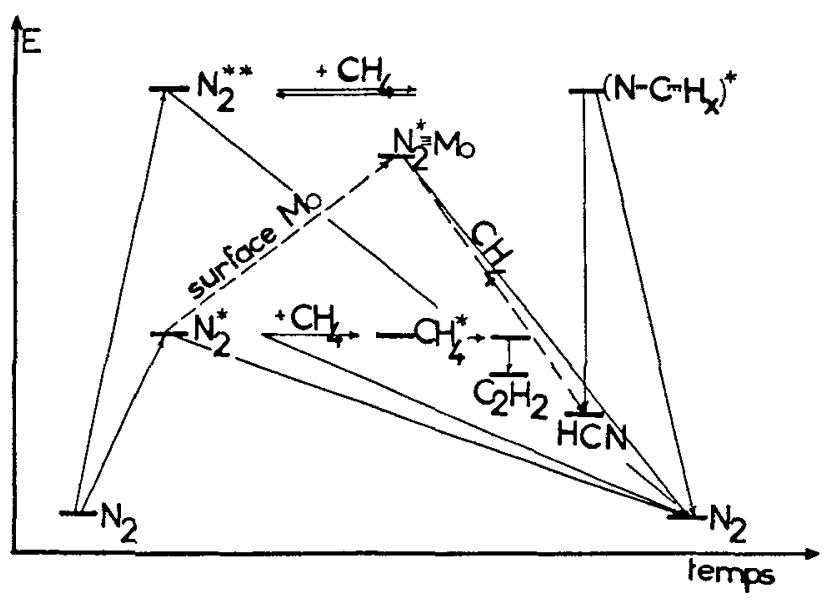

Fig. 16. -- Catalysis mechanism of the reaction $\mathrm{N}_{2}-\mathrm{C}_{2} \mathrm{H}_{2}$ (after [68]). 
the reaction is represented on figure 16 , where $\mathrm{N}_{2}^{* *}$ corresponds to $\mathrm{N}_{2}\left(\mathrm{C}^{3} \Pi_{\mathrm{u}}\right)$ and $\mathrm{N}_{2}^{*}$ to $\mathrm{N}_{2}\left(\mathrm{~A}^{3} \Sigma_{\mathrm{u}}\right)$. The fixation reaction with, as a first step, dissociation of $\mathrm{N}_{2}\left(\mathrm{C}^{3} \Pi_{\mathrm{u}}\right)$ is favorized by a high vibration energy (low pressure) but the most important step is the quenching of the highly excited formed $\mathrm{HCN}$, favorized by a high rotation temperature (high pressure) as indicated by the experimental results. The introduction of a molybdenum grating in the mixing area of the cold methane and nitrogen plasma was noted [68] to produce an increase in HCN conversion. This seems to be due to a catalytic effect of the grating which leads to a decrease of the excitation transfer $\left(\mathrm{C}_{2} \mathrm{H}_{2}\right)$ and an increase of the fixation reaction $(\mathrm{HCN})$. Neglecting a possible quenching effect on the surface of the hot metal (because a simple calculation leads to a quenching rate smaller than $10^{5} \mathrm{~K} / \mathrm{s}$ ), the experimental results are interpreted [68] as a catalytic effect at the surface of the metal : the effect increases with the number of wires and the position of the grating is very important, the maximum of conversion being obtained right in the mixing zone. If the wires are vapourized the quantity of fixed nitrogen decreases. Figure 16 indicates the mechanism proposed by Rapakoulias [68] : a chimisorption by the metal of an excited $A^{3} \Sigma_{u}^{+} N_{2}$ molecules breaking the N-N bounding, the nitrogen atoms reacting with $\mathrm{CH}_{4}$ or its fragments to give an unstable molecule $\left(\mathrm{N} . . \mathrm{C} \ldots \mathrm{H}_{x}\right)^{*}$. By desorption of the surface, a stabilized $\mathrm{HCN}$ molecule is formed.
With this effect, it is possible to increase the $\mathrm{HCN}$ formation by as much as $50 \%$.

2.5 EXAMPle : ORganic REactions WTTH METASTABLES OXYGEN MOLECULES. - The excited metastable states of atoms or molecules ionized or not, play a very important role in chemical reactions under plasma conditions. These states may act along different ways. Their high internal energy may be relaxed by collisions and help to pass the activation barrier of the reaction. In other cases it is the electronic configuration of the metastable state that gives to the reaction a stereochemistry which is different from that of the fundamental state. The exact role of the metastable states is, however, not yet well known due to the difficulty of producing them in a specific manner and to study their population (no radiative deexcitation).

One of the most extensively studied metastable state is the $\mathrm{O}_{2}{ }^{1} \Delta_{\mathrm{g}}$ because of its interesting properties for organic reactions. The excited states ${ }^{1} \Delta$ and ${ }^{1} \Sigma$ have almost the same bounding length and identical potential curves as the fundamental state ${ }^{3} \Sigma$. The radiative deexcitation of $\mathrm{a}^{1} \Delta$ to $\mathrm{X}^{3} \Sigma$ is not possible due to the selection rules but is possible with the spin orbit coupling and the life time of ${ }^{1} \Delta$ is $3900 \mathrm{~s}$ [141]. It is the same with ${ }^{1} \Sigma$ which life time is $12 \mathrm{~s}$. However, as the collisions dipole transitions between these states become more probable, the following reactions can take place:

$$
\begin{array}{ll}
{ }^{1} \Delta+{ }^{1} \Delta \rightarrow{ }^{3} \Sigma+{ }^{3} \Sigma+\mathrm{hv} & \left(\lambda=6340 \AA, \tau=1.5 \mathrm{~s}, k=5 \times 10^{-23}\right) \\
{ }^{1} \Sigma+{ }^{1} \Sigma \rightarrow{ }^{3} \Sigma+{ }^{3} \Sigma+\mathrm{hv} & \left(\lambda=3802 \AA, \tau=0.3 \mathrm{~s}, k=8.3 \times 10^{-23}\right) \\
{ }^{1} \Delta+{ }^{1} \Sigma \rightarrow{ }^{3} \Sigma+{ }^{3} \Sigma+\mathrm{hv} & \left(\lambda=4770 \AA, \tau=1.7 \mathrm{~s}, k=4 \times 10^{-23}\right) .
\end{array}
$$

The $\mathrm{O}_{2}{ }^{1} \Delta$ is mostly produced with a $\mathrm{HF}$ or $\mathrm{MW}$ discharge in pure oxygen [142 to 145] avoiding the destruction of the metastable $\left({ }^{1} \Delta\right)$ with impurities and a pollution with the electrodes. For example figure 17 shows the experimental set up of Dumas [145], the power of the $\mathrm{HF}$ source varying from 0 to $250 \mathrm{~W}$ and the frequency between 55 and $70 \mathrm{MHz}$. With such discharges the states obtained are [146] :

$$
\begin{gathered}
\mathrm{O}_{2}\left({ }^{3} \Sigma\right): 70 \text { to } 80 \%, \mathrm{O}_{2}\left({ }^{1} \Delta\right): 5 \text { to } 20 \%, \\
\mathrm{O}_{2}\left({ }^{1} \Sigma\right): 10^{-2} \%, \quad \mathrm{O}\left({ }^{3} \mathrm{P}\right): 10 \text { to } 20 \%, \\
\mathrm{O}_{3}: 1 \text { to } 2 \% .
\end{gathered}
$$

The $\mathrm{O}$ and $\mathrm{O}_{3}$ species are very undersirable because they desactivate very quickly the $\mathrm{O}_{2}\left({ }^{1} \Delta\right)$. Also their reactivity with most organic species is much more important than the reactivity of $\mathrm{O}_{2}\left({ }^{1} \Delta\right)$, so they must be eliminated to study the reactions with the singulet oxygen. That is why in its experimental set up Dumas has disposed, just before the induction coupling, a small tank of mercury to be vaporized (R Fig. 17a). In the discharge one has the reactions :

$$
\begin{aligned}
& \mathrm{Hg}\left({ }^{3} \mathrm{P}\right)+\mathrm{O}_{2}\left({ }^{3} \Sigma\right) \rightarrow \mathrm{Hg}\left({ }^{1} \mathrm{~S}\right)+\mathrm{O}_{2}\left({ }^{1} \Delta \text { or }{ }^{1} \Sigma\right) \\
& \mathrm{Hg}+\mathrm{O} \rightarrow \mathrm{HgO} \\
& \mathrm{HgO}+\mathrm{O} \rightarrow \mathrm{Hg}+\mathrm{O}_{2} .
\end{aligned}
$$

The last two reactions $((5)$ and (6)) are fast enough to withdraw almost all the oxygen and to avoid the formation of

$$
\mathrm{O}_{3}\left(\mathrm{O}_{2}+\mathrm{O}+\mathrm{O}_{2} \rightarrow \mathrm{O}_{3}+\mathrm{O}_{2}: k=6 \times 10^{-34}\right) \text {. }
$$

The excess of mercury is then collected in a cold trap.

The $\mathrm{O}_{2}\left({ }^{1} \Delta\right)$ is analyzed through the emission of the $6340 \AA$ band due to the collision reaction (1) and through the calorimetric effect of the partial desexcitation of $\mathrm{O}_{2}\left({ }^{1} \Delta\right)$ on a heated wire $\left(\mathrm{R}_{0}\right.$ Fig. 17a) covered with a catalyser : cobalt oxide. The maximum quantity of $\mathrm{O}_{2}{ }^{1} \Delta$ (rate of $12 \%$ ) is obtained for a 


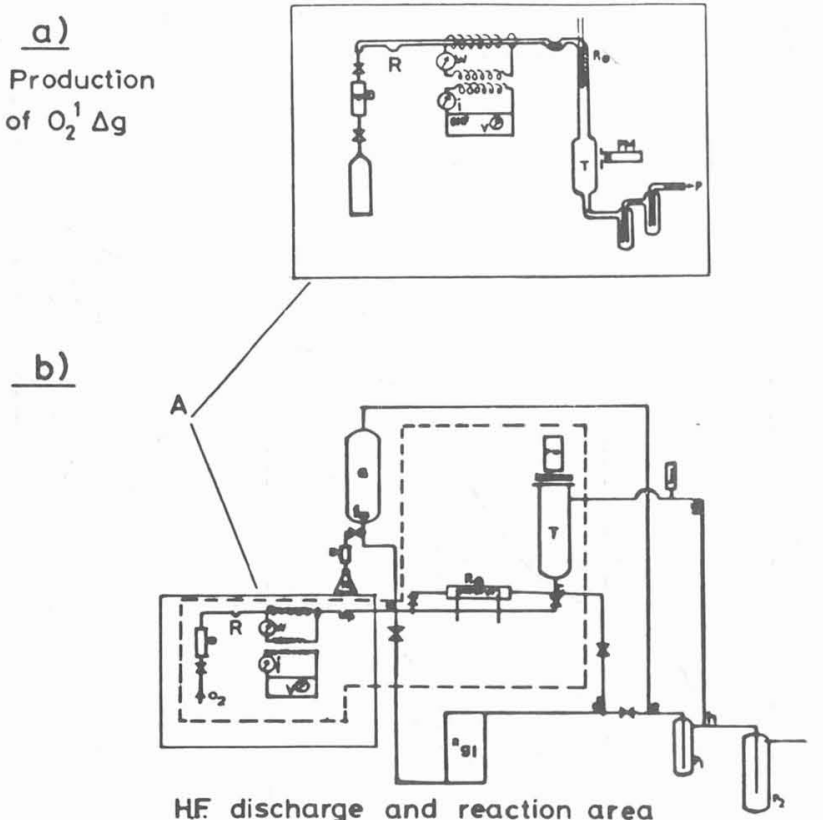

c)

Reaction devices

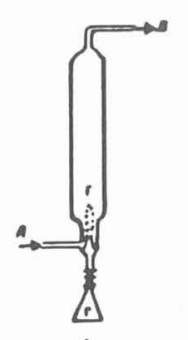

A
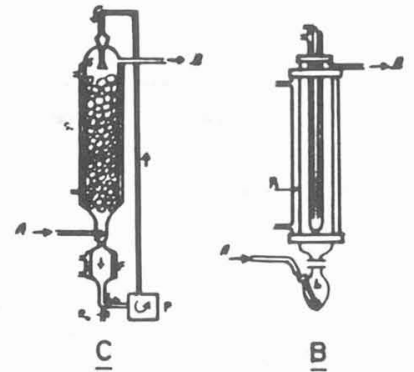

Fig. 17. - HF reactor for organic compounds (after [145]).

power of $30 \mathrm{~W}$ and a pressure of 3 torrs. The $\mathrm{O}\left({ }^{3} \mathrm{P}\right)$ density is measured with the two reactions :

and

$$
\mathrm{O}+\mathrm{NO} \rightarrow \mathrm{NO}_{2}+\mathrm{hv} \quad\left(k=10^{-17}\right)
$$$$
\mathrm{O}+\mathrm{NO}_{2} \rightarrow \mathrm{NO}+\mathrm{O}_{2} \quad\left(k=10^{-12}\right) .
$$

The $\mathrm{O}_{3}$ density is obtained by a chemical method : absorption of $\mathrm{O}_{3}$ on silica gel at the liquid nitrogen temperature, and then reaction with iodine

$$
\mathrm{O}_{3}+2 \mathrm{I}^{-}+2 \mathrm{H}^{-} \rightarrow \mathrm{O}_{2}+\mathrm{H}_{2} \mathrm{O}+\mathrm{I}_{2} \text {. }
$$

The measurements show for example that at 1 torr with an oxygen flow rate of $20 \mathrm{Nml} / \mathrm{min}$ the $\mathrm{O}_{3}$ density decreases from $4 \%$ to $0.1 \%$ in presence of $\mathrm{Hg}$ vapour.

After the discharge the desexcitation kinetic of ${ }^{1} \Delta$ is given by :

$$
\begin{aligned}
\frac{\left.\partial{ }^{1} \Delta\right]}{\partial \mathrm{t}}=k_{\mathrm{w}}\left[{ }^{1} \Delta\right]+\left(k_{\mathrm{O}_{2}}\left[\mathrm{O}_{2}\right]+k_{\mathrm{D}}[\mathrm{O}]\right. & \left.+k_{\mathrm{O}_{3}}\left[\mathrm{O}_{3}\right]\right) \times \\
& \left.\times\left[{ }^{1} \Delta\right]+k_{\mathrm{c}}{ }^{1} \Delta\right]^{2}
\end{aligned}
$$

the first term corresponding to a desactivation on the wall. The calculations made by Dumas [145] shows that with a glass tube of $0.5 \mathrm{~cm}, 1 \mathrm{~m}$ after the discharge zone the population of $\mathrm{O}_{2}\left({ }^{1} \Delta\right)$ is only decreased of 15 to $30 \%$.

It is then possible to drive the $\mathrm{O}_{2}{ }^{1} \Delta$ to either tank $G$ for a gaseous phase reaction or in a tank $R$ where the organic product is in liquid phase (Fig. 17b). The different reactors used are represented on figure $17 c$. A for reactions with gas or liquid with a high vapour pressure, B for liquids with low vapour pressure and $\mathrm{C}$ for solids products dissolved in a convenient solvent.

Due to its analogy with the carbon-carbon bonding of an alcine one observes a specific chemical reactivity of $\mathrm{O}_{2}\left({ }^{1} \Delta\right)$ as for example its fixation on a double bonding $\mathrm{C}=\mathrm{C}$ including a hydrogen atom in $\alpha$ of the bonding and in a cis position. If there is no $\mathrm{H}$ in $\alpha$ it is possible to get dioxetanes more or less stable giving a rupture of the bonding. But the most interesting case is the reaction with a double bonding in the aromatic cycle or in the heterocycle. One will find a summary of the reactions studied by Dumas in [147 to 149 ].

3. Plasma chemistry with condensed phases. - A high temperature plasma (arc or HF at atmospheric pressure) is first a source to get high populations of excited states either by Boltzmann distribution at high temperature or by transfers with metastable (for example in an argon DC plasma jet it is possible to obtain density of the atomic metastables up to $6 \times 10^{13} \mathrm{part} / \mathrm{cm}^{3}$ and if one injects cold nitrogen into such a plasma the excitation transfert

$$
\mathrm{Ar}^{\mathrm{m}}+\mathrm{N}_{2}(\mathrm{X}) \rightarrow \mathrm{Ar}+\mathrm{N}_{2}(\mathrm{C})
$$

allows overpopulation factors in the range $10^{15}-10^{20}$ ). However when these high temperature plasmas are used for solid materials treatment they are usually considered in the first approximation as a source of energy in LTE. So using the LTE hypothesis one calculates the thermodynamic and transport properties of the plasma itself. And then one must calculates mass and heat transfert between plasma and particles or solids and study successively fusion, vaporisation, chemical changes and condensation.

\subsection{THERMODYNAMIC AND TRANSPORT PROPERTIES} OF THE PLASMA. - 3.1.1 Thermodynamic properties. - For reactions in the gaseous phase we have seen that the concentration of the different species is the important parameter but for heat transfer the two important parameters are the specific heat and the enthalpy. The specific heat, is by definition,

$$
C_{p}=-\left(\frac{\partial \hat{H}}{\partial T}\right)_{p}
$$

where $\hat{H}$ is the mass enthalpy of the mixture. One obtains [150]

$C_{p}=\frac{1}{M}\left[\sum_{i=1}^{N} x_{i} c_{p i}+\sum_{i=1}^{N} x_{i}\left(H_{i}-m_{i} \hat{H}_{i}\right)\left(\frac{\partial \log x_{i}}{\partial T}\right)_{p}\right]$ 
where $c_{p i}$ is the specific heat at constant pressure, $x_{i}$ the mole fraction, $H_{i}$ the enthalpy of the species $i$ and $M$ the total mass of the mixture. In this expression the first term is the frozen $\bar{c}_{p}$ and the second the reaction term $c_{p r}$ which becomes important and shows maxima each time there is dissociation, ionisation or chemical reaction. For example [150] figure 18 shows the different components of the specific heat at constant pressure for the system $1 \mathrm{C}, 4 \mathrm{H}, 20$ and $2 \mathrm{Fe}$ at atmospheric pressure. The very reactive nature of the mixture is indicated by the form of the $C_{p}$ curve.

$C_{p}(\operatorname{cog} n)$

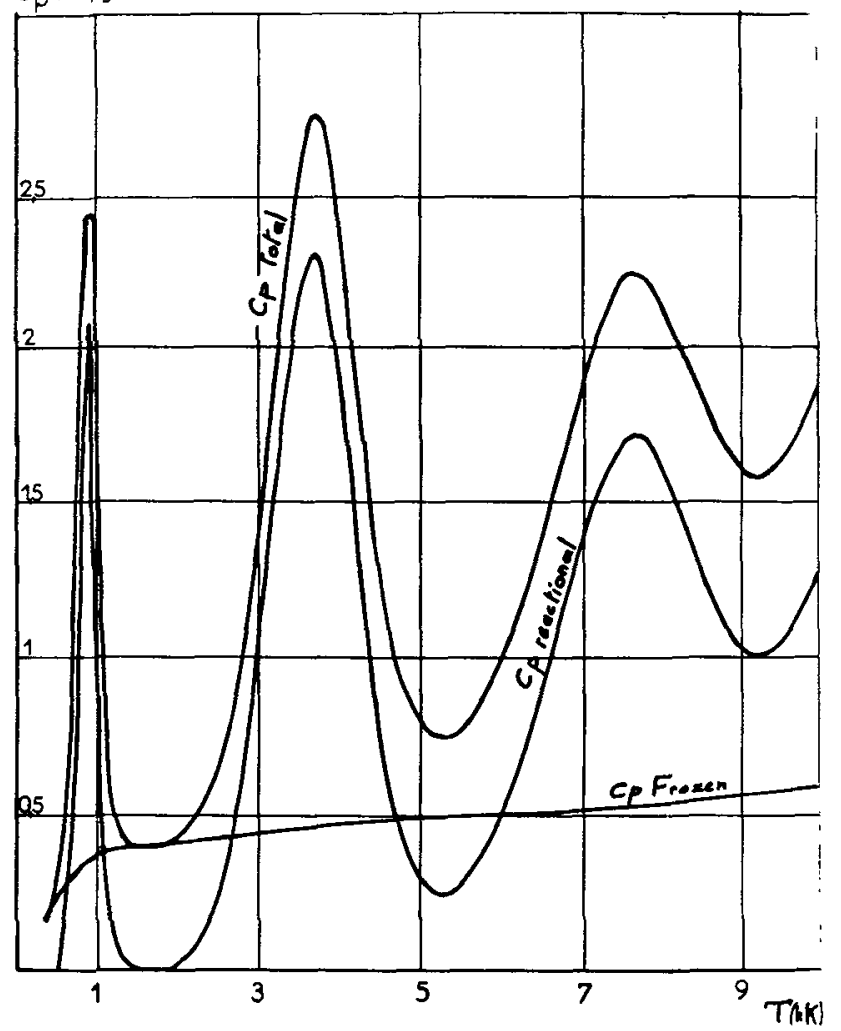

Fig. 18. $-C_{p}$ versus $T$ for the system C.H.O. $\mathrm{F}_{\mathrm{e}}, \mathrm{e}^{-} / 1.4 .3 .2 .0[150]$.

Figure 19 shows the enthalpy of the same mixture obtained by integration of $C_{p}$.

3.1.2 Transport properties. - The levels of mass and heat transfer between the plasma and the introduced material are determined by the viscosity and thermal conductivity of the plasma. In the LTE hypothesis these parameters are calculated by solving the integro-differential Boltzmann equation, usually by the Enskog's method of successive approximations $[151,152]$. The perturbation function is found [153] by using Sonine polynomial of order $k$, the problem being to find the minimum value of $k$ that gives the best convergence of the series. For example [154 to 158 ] found that it is sometime necessary to carry out the calculations up to $k=4$. In this calculations it is necessary to know the interactions

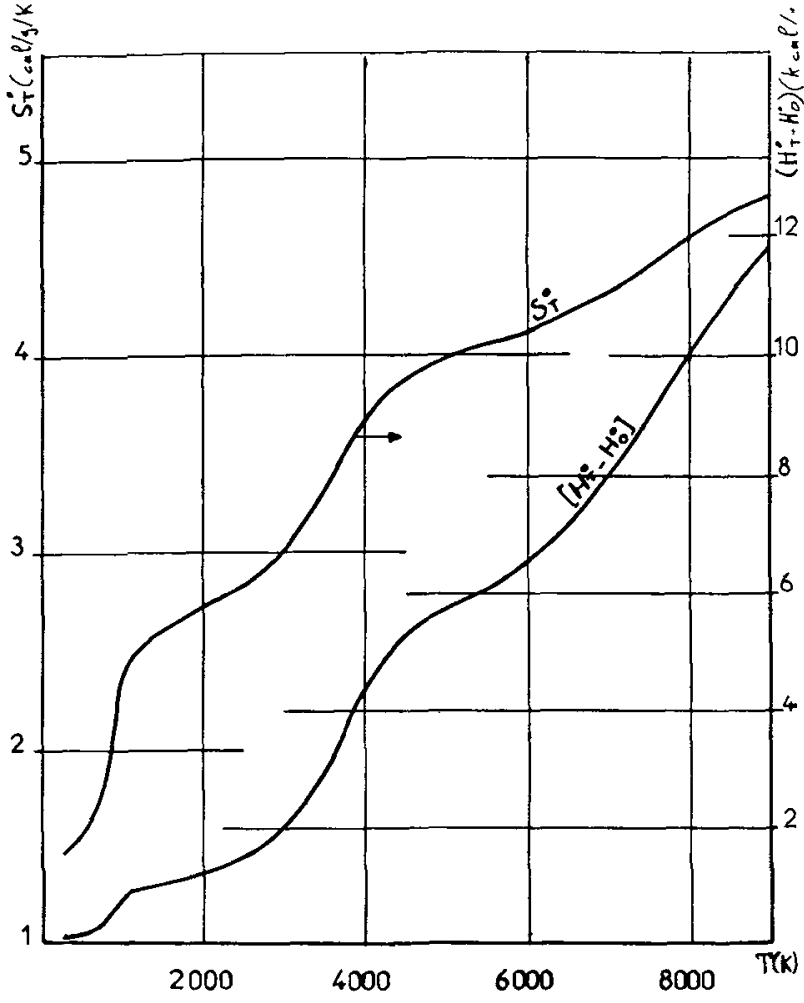

Fig. 19. - System C. 4 H.30.2 Fe [150].

potentials to determine the collision integrals. Unfortunately their is no data for plasmas of complex mixtures ( $\mathrm{C}, \mathrm{H}, \mathrm{O}$ for example), and even for these who are known there is a large uncertainty about the interaction potential. The calculation of the viscosity is made with the pressure tensor [151]. For the thermal conductivity one must take into account the reaction conductivity [159] and the internal thermal conductivity [160]. Figure 20 shows the importance of the reaction conductivity when the ionisation of argon occurs and figure 21 shows the importance of the dissociation of hydrogen in a mixture or $\mathrm{Ar}-\mathrm{H}_{2}$ [161].

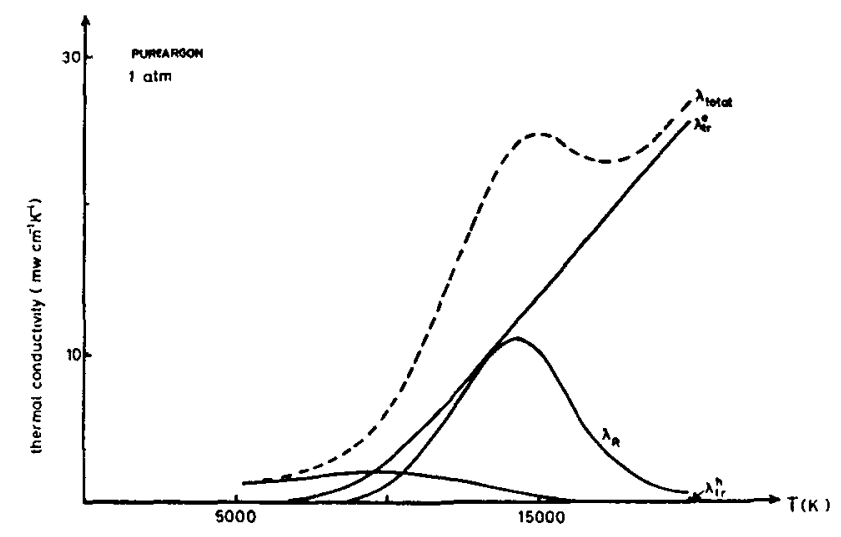

Fig. 20. - Thermal conductivity of argon versus temperature (after [161]). 


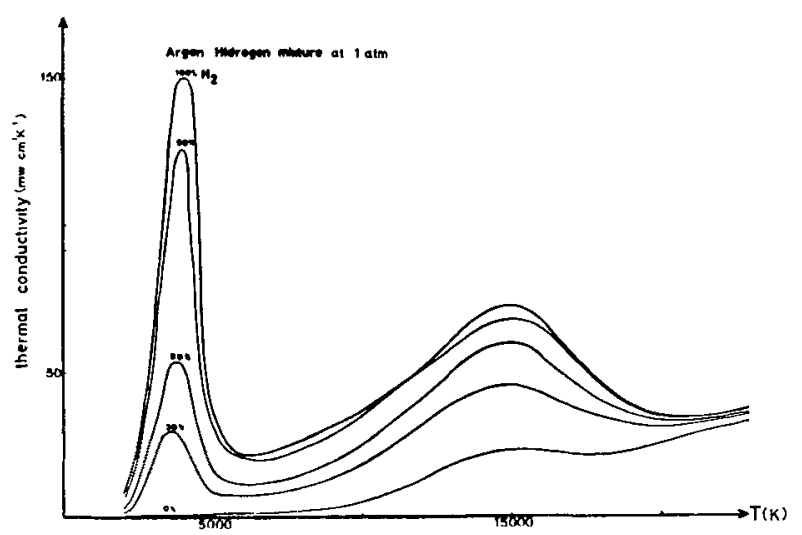

Fig. 21. - Thermal conductivity of argon-hydrogen mixtures versus $T$ (after [161]).

3.2 Heat AND MASS TRANSFer. - For a partially ionized gas, dimensional analysis leads to empirical correlations for heat transfer through the Nusselt number [162]

$$
\mathrm{Nu}=f(\operatorname{Pr}, \operatorname{Re}, \mathrm{Sc}, \xi, \varphi)
$$

where $\mathrm{Pr}, \mathrm{Re}, \mathrm{Sc}$ are respectively the Prandlt, Reynolds and Schmidt number, $\xi$ the ionization degree and $\varphi=e V_{\mathrm{F}} / k T$. The differents correlations used are listed in tables I and II. Usually the plasma transport properties used to calculate the reduced numbers are integrated over the range of temperature considered (plasma temperature, particle temperature).

When the material treated is used as electrode the problem becomes very complex [163 to 166]. The heat flux going through the anode being :

$$
q_{\mathrm{a}}=q_{\mathrm{c}}+q_{\mathrm{r}}+j_{\mathrm{e}}\left(\frac{5}{2} \frac{k T_{e}}{e}+V_{\mathrm{a}}+\varphi_{\mathrm{a}}\right)
$$

where $q_{\mathrm{c}}$ is the conduction and convection term, $q_{\mathrm{r}}$ the radiative flux, $V_{\mathrm{a}}$ the anode fall, $\varphi_{\mathrm{a}}$ the work function of the anode material. $T_{\mathrm{c}}$ the electronic temperature and $j_{\mathrm{c}}$ the electron current density.

The particle trajectoires are obtained by solving the Basset-Boussinesq-Oseen equation [167 to 171]. In this equation, the velocity variation is expressed
Table II. - Correlation in the boundary layer.

$$
\begin{array}{ll}
\mathrm{Nu}_{\mathrm{loc}}=0.323 \mathrm{Re}_{\mathrm{loc}}^{1 / 2} \operatorname{Pr}^{1 / 3} & \operatorname{Pr}>0.7 \text { theoretical } \\
\mathrm{Sh}_{\mathrm{loc}}=0.332 \operatorname{Re}_{\mathrm{loc}}^{1 / 2} \mathrm{Sc}^{1 / 3} & \operatorname{Re}_{\mathrm{loc}}<10^{5} \text { results } \\
\mathrm{Nu}=0.037 \operatorname{Re}^{0.8} \operatorname{Pr}^{1 / 3} & \operatorname{Pr}>0.7 ; \operatorname{Re}>10^{5} \\
\mathrm{Nu}=0.02 \operatorname{Re}_{\mathrm{loc}}^{0.87} \operatorname{Pr}^{0.33} & \text { Hot gas strinking on a wall }
\end{array}
$$

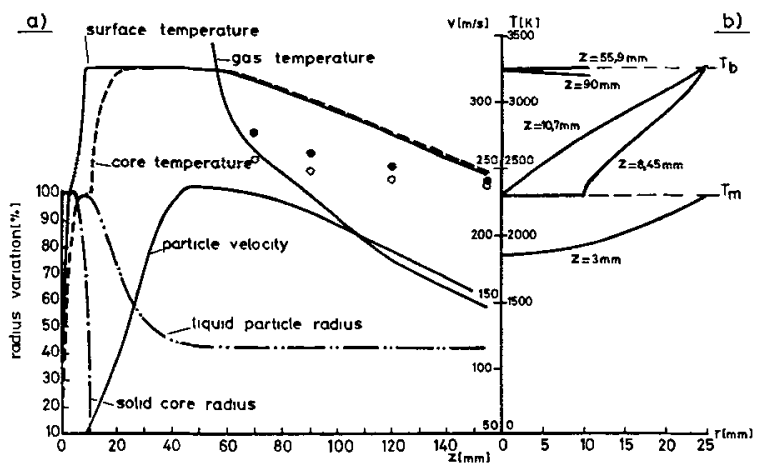

Fig. 22. - Temperature distribution for $\mathrm{Al}_{2} \mathrm{O}_{3}$ particles (after [100]).

through the drag coefficient $C_{\mathrm{D}}$ expressed as a function of the Reynolds number [167 to 171] (see Table III). For example figure 22 shows the velocity and temperature distribution of alumina $40 \mu \mathrm{m}$ particles injected in an hydrogen plasma jet [100]. This distribution calculated from the preceeding equations (knowing plasma temperature and velocity) is in good agreement with the measurement performed on 20-28 $\mu$ particles (dark circles) and 50-63 $\mu \mathrm{m}$ particles (open circles).

For heat transfer one usually supposes that the whole energy coming from the plasma is absorbed by specific heat and lost by radiative transfer. For example figure 23 shows [170] the calculated temperatures reached by alumina particles injected into a HF argon plasma (open circles : solid particle, dark circle liquid droplet and partially shaded circle : partially melted particle). However in such a calculation an important phenomenon has been neglected, the influence of the particle thermal conductivity and for example the experimental results of Lesin-

Table I. - Correlation for Nusselt Number.

$$
\begin{gathered}
1.86\left(\operatorname{Re} \operatorname{Pr} \frac{\mathrm{L}}{\mathrm{D}}\right)\left(\frac{\overline{\mathrm{u}}}{\mathrm{u}_{\mathrm{f}}}\right)^{0.14} \\
0.026 \operatorname{Re}^{0.8} \operatorname{Pr}^{1 / 3}\left(\frac{\overline{\mathrm{u}}}{\mathrm{u}_{\mathrm{f}}}\right)^{0.14} \\
0.023 \operatorname{Re}^{0.8} \operatorname{Pr}^{\mathrm{m}} \\
7+0.025(\operatorname{Re} \operatorname{Pr})^{0.8} \\
5+0.025(\operatorname{Re} \operatorname{Pr})^{0.8}
\end{gathered}
$$

\section{Conditions}

-

$\operatorname{Re}<200 ; \mathrm{L} / \mathrm{D}>10$ wall with $\mathrm{T}=$ constant

$\operatorname{Re}>210^{4} ; 0.6 \leqslant \operatorname{Pr}<100 ; \mathrm{L} / \mathrm{D}>10$

$0.7<\operatorname{Pr}<100 ; \operatorname{Re}>10^{4} ; \mathrm{L} / \mathrm{D}>60$; $\mathrm{m}=0.3$ for cooling; $\mathrm{m}=0.4$ for heating

$\operatorname{Re} \operatorname{Pr}>100$ heat flux to the wall is constant $200<\operatorname{Re} \operatorname{Pr}<10^{4} \mathrm{~T}_{\text {wall }}=$ constant
References 
Table III. - Correlations for the drag coefficient (after [84]).

$$
\begin{aligned}
& \operatorname{Re} \\
& \overline{-} \\
\operatorname{Re}< & 0.1 \\
0.1 \leqslant & \operatorname{Re}<1 \\
1 \leqslant & \operatorname{Re}<20 \\
20 \leqslant & \operatorname{Re}<200
\end{aligned}
$$

$S_{1}$ is a shape factor; for thin disks $S_{1}=8 / 3 \pi$.
$\mathrm{C}_{\mathrm{D}}$ Flakes : e $0.026 D_{\mathrm{p}}$ $24 \mathrm{~S}_{1} / \mathrm{Re}$ $\left(24 \mathrm{~S}_{1} / \mathrm{Re}\right)\left(1+3 \mathrm{~S}_{1} \mathrm{Re} / 16\right)$ $(20.4 / \operatorname{Re})\left(1+0.136 \operatorname{Re}^{0.803}\right)$ $(20.4 / R e)\left(1+0.138 R^{0.793}\right)$
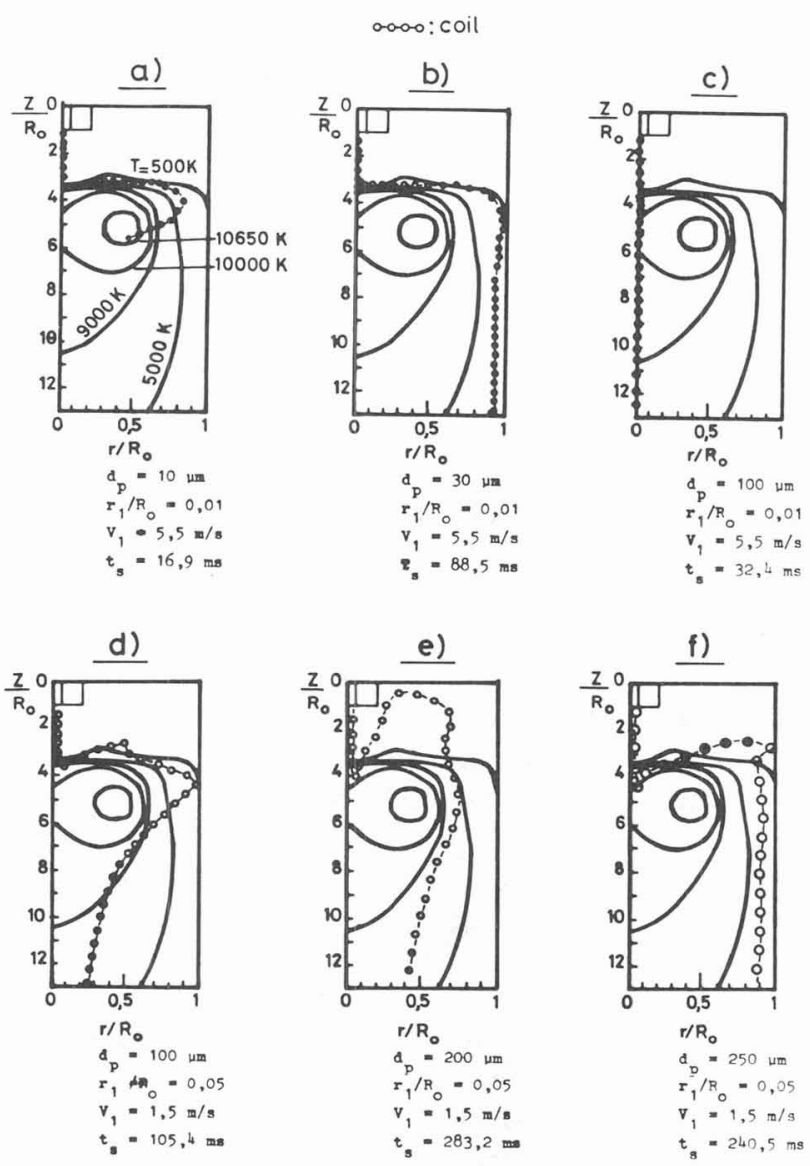

Fig. 23. - Particle trajectories (after [170]).

ski [100] shows more than $600 \mathrm{~K}$ of difference between the calculated and measured temperatures. This is due to the fact that for low thermal conductivity the heat flux leads to a fused zone at the surface of the particle and the vapour leaving the partially melted particle completely modifies the heat exchange [173]. Figure 24 shows the application of the calculation of the temperature history of iron particles of different diameters in a HF plasma, one has to note the change of slope near the Curie temperature due to the singular point of the thermal diffusivity. But unfortunately one has to emphasize that most of the thermal properties of the solids at high temperature are not well known. a)
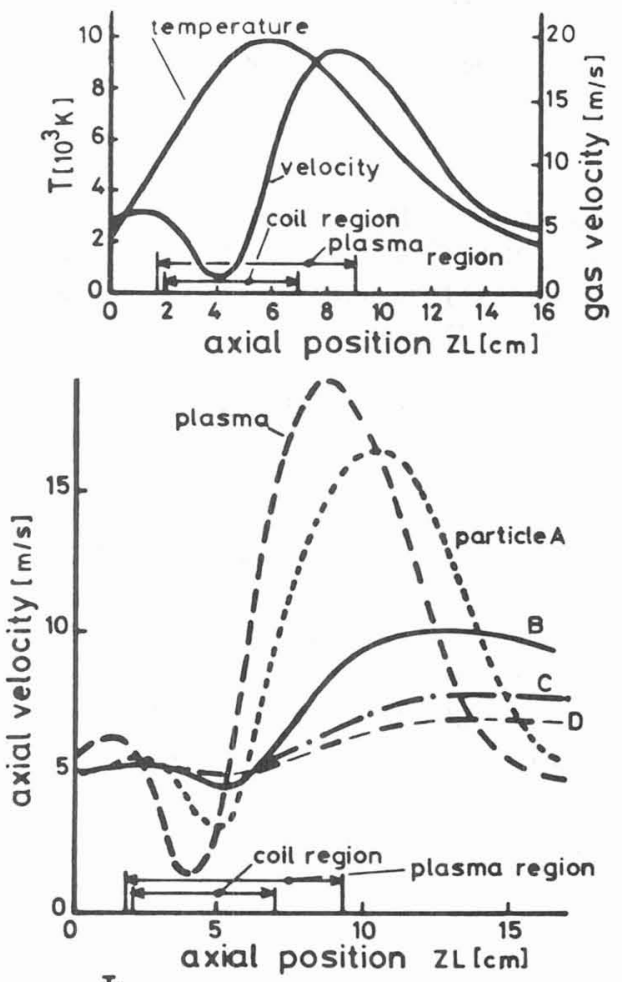

b)

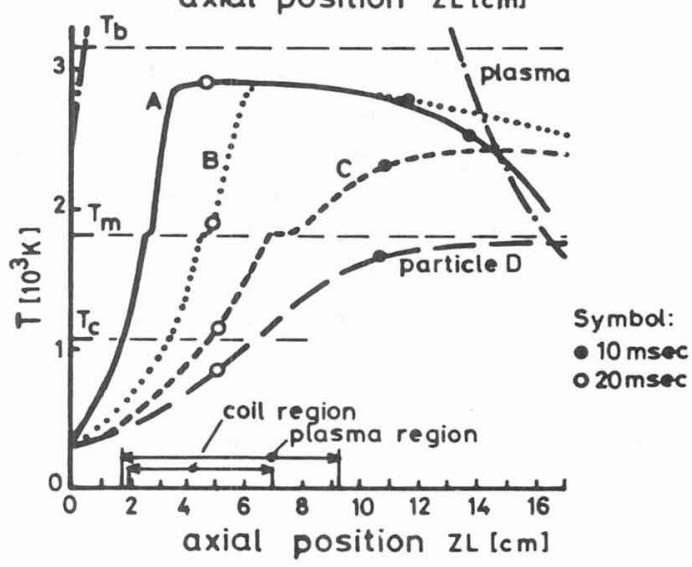

Fig. 24. - Predicted particle surface temperature and velocity (after [173]).

3.3 Physical Changes of Solid materials in PLASMA. - 3.3.1 Plasma spraying. - Since 1960 DC plasma jets have been used to melt a powder feed and project the droplets at high velocity against a 
material to be coated. Any material, provided a few hundred degree Celsius between its fusion temperature and its vaporization or decomposition temperature may be sprayed. We do not wish here to make a general review of the sprayed materials (see for example [174 to 176]) or of their use, but to emphasize the physical problems encountered that need to be solved. A plasma sprayed deposit consists of successive layers of material built up by the impact of molten droplets, projected at high velocity, which flatten against the substrate and solidify very rapidly. As we have seen the plasma jets are very inhomogeneous with high temperature gradients (see for example Fig. 5) corresponding to high transport properties gradient (see for example Fig. 21). The main problem is to introduce the particles inside the hot area of the plasma, which in very difficult because of its high viscosity. Measurement of the velocity of $18 \mu \mathrm{m}$ diameter alumina particles at the end of the injector disposed orthogonaly to the plasma jet [104] shows that the particles with a velocity smaller than $20 \mathrm{~m} / \mathrm{s}$ could not penetrate the plasma jet and remain on the periphery and cannot be melted and on the contrary with a velocity greater than $40 \mathrm{~m} / \mathrm{s}$ they just go through the jet and are not melted. Unfortunately on a commercial scale the granulometry of the particles injected is rather large and it will be possible to give the good speed only to the particles in the center of the distribution. To get a good plasma coating one needs to have only completely melted particles flattening on the target and to eliminate the particles travelling at the periphery of the jet at a velocity of a few $\mathrm{m} / \mathrm{s}$ compared to the velocity of the particles travelling in the central zone (greater than $100 \mathrm{~m} / \mathrm{s}$ see Fig. 8). Due to the difference in kinetic energy, the particles along the periphery can be eliminated by a compressed air blast normal to the plasma jet close to the substrate [177]. For particles that penetrate the plasma jet, due to the high temperature and velocity gradients of the plasma (see Fig. 5 and 7) and large size distribution, the spray stream produced will contain particles with a wide range of velocity and temperature. If they are molten they will flatten on impact with the substrate. Their degree of flattening [178, 179] (ratio of the diameter of flattened disc $(D)$ to diameter of the initial drop $(d)$ ) is given by the following equation

$$
D / d=1.29\left(\frac{\rho v d}{\mu}\right)^{0.2}
$$

where $\rho$ is the liquid density, $\mu$ the liquid viscosity, $v$ the droplet impact velocity. Substituting appropriate values for $\mathrm{Al}_{2} \mathrm{O}_{3}$ in the velocity range $100 / 400 \mathrm{~m} / \mathrm{s}$ gives $D / d: 3-6$ which seems to be in reasonable agreement with various experimental observation $[180$, 181]. With such flattening, plasma spraying conditions are very similar to those occuring during splat quenching of metals. The heat transfer rate to the sub- strate [182] may be estimated of the order of $10^{5} \mathrm{Wm}^{-2} \mathrm{~K}^{-1}$. Applying this to $\mathrm{Al}_{2} \mathrm{O}_{3}$ it gives a cooling rate of $10^{7} \mathrm{~K} \cdot \mathrm{s}^{-1}$ and a freezing time of $10 \mu \mathrm{s}$. The zone of thermal effect in the underlying material is therefore quite small and temperature gradients reach $\simeq 10^{5} \mathrm{~K} . \mathrm{cm}^{-1}$. The coating has a sandwich like structure as shown in figure 25 and its properties can be regarded as resulting from the deformation and solidification processes of individual particles and their interaction on contact. The wetting and flow properties of the liquid droplets are of first importance since they will influence porosity and adhesion properties. The porosity is related to the particle temperature and velocity on impact. As shown by Vardelle [104] : the porosity decreases from $22 \%$ to $10 \%$ if the velocity is increased by $150 \mathrm{~m} / \mathrm{s}$ with alumina particles. The factors controlling the adhesion are not well understood. One point of view suggests that adhesion is controlled purely by mechanical factor [183] (interlocking of the coating with the rough substrate surface) another is' that chemical interaction occurs between particle and substrate [184, 175]. However, except in the case where a strong exothermic reaction occurs between two molten metals (nickel aluminide spraying [185]), it is difficult to see how an interaction layer of any significant depth can be formed. Even assuming values for diffusion coefficients $(D)$ in the substrate of the order of that near the melting point $\left(10^{-9} \mathrm{~cm}^{2} \mathrm{~s}^{-1}\right)$ the diffusion depth $(x)$ given by $x=\sqrt{D t}$ is of the order $10 \AA$ for a contact of $10 \mu \mathrm{s}$. But on the contrary after grit blasting the adhesion decreases with the thickness of the oxide film formed on the substrate. Epitaxial growth and bonding occurs only when the substrate is at high temperature (greater than $1300^{\circ} \mathrm{C}$ for $W$ spraying on $W$ ). So a lot of work remains to be done before the mechanism is properly understood.

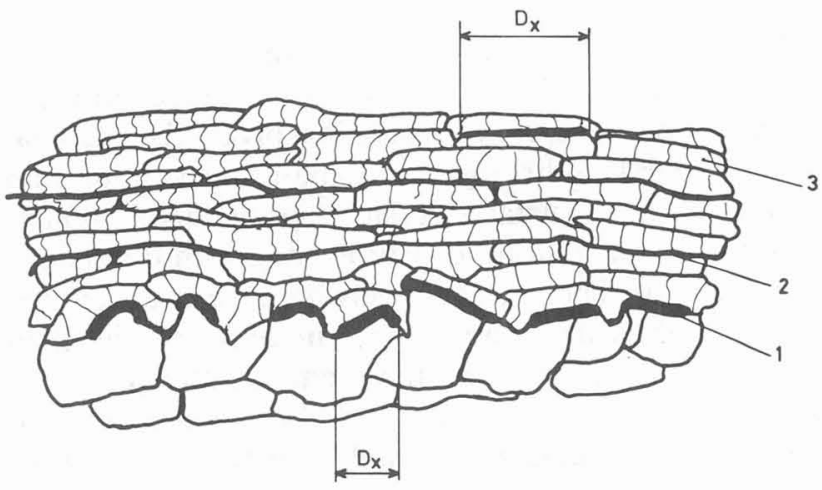

Fig. 25. - Texture of plasma sprayed coating : (1) contact surface between the coating and substrate; (2) contact surface between layers; (3) contact surface between particles. $\left(D_{x}\right)$ diameter of the fused contact surface portion (after [14]).

The crystal structure of the coating is often very different from the initial material crystal structure due to extremely rapid cooling and one observes the suppression of crystallisation or the formation 
of solid metastable phases [185 to 189]. Some effects of preferred orientation of the crystals relative to the surface have also been observed with hexagonal structure (coating with controlled friction coefficients) [190] but they are not clearly understood.

3.3.2 Spheroidisation. - Melting of a particle results in the formation of a spherical drop under the action of surface tension forces and this shape is usually retained by the solid particle after solidification $[191,192]$. For example this treatment is used for spheroidisation of $\mathrm{Fe}_{3} \mathrm{O}_{4}$ for photocopying and $\mathrm{UO}_{2}$ for dispersed nuclear fuels, or to get structural changes as in the dissociation of zircon to $\mathrm{ZrO}_{2}$ and $\mathrm{SiO}_{2}$ allowing a preferential dissolution and the preparation of $\mathrm{ZrO}_{2}$ [193]. Spheroidisation of quartz, clays, kyanite, mullite and others alumino-silicates results $[194,195]$ in the formation of glasses of high melting point. The spheroidisation may also provide a purification effect by evaporation of some impurities (for example $\mathrm{Fe}, \mathrm{Mo}, \mathrm{Na}$ from $\mathrm{Al}_{2} \mathrm{O}_{3}$ [14]).

RF plasma torches are generally used for spheroidisation of particles (long residence time and no pollution by electrodes) when a high purity is required. $\mathrm{DC}$ or $\mathrm{AC}$ arc plasma jets give rise to limitations in the particle size that may be treated because of the short residence time. Plasma furnaces with fluid convective cathodes (FCC) [196 to 198] or fluidized bed [199] which give longer residence times (mean temperature $5000 \mathrm{~K}$ and mean velocity a few $\mathrm{m} / \mathrm{s}$ ) are more suitable for large scale spheroidisation of larger particles. From a physical point of view one has to mention that the FCC uses the Maecker effect [200 to 202] that is to say magneto-hydrodynamic pumping near the cathode tip (for example at atmospheric pressure one has a reduction of the pressure of $0.02 \mathrm{~atm}$ at the cathode tip of an arc working in hydrogen with $500 \mathrm{~A}$ ).

3.3.3 Vaporisation. - The vaporisation of a particle at atmospheric pressure requires a large amount of energy because, as vaporisation proceeds, the heat must be carried through the expanding vapour film on the particle surface (a silica particle of $200 \mu \mathrm{m}$ would produce a cloud of vapour of $5 \mathrm{~mm}$ diameter). A number of theoretical models have been developed [203 to 205] with probably an increase of the heat transfer due to the higher temperature of electrons [203, 206], specially when the material is used as electrode. To achieve the high transfer rate one uses mostly rotating plasma furnaces [207 to 208] or arc transfered to the material being vaporized (using the material as anode see $\S 3.2$ ) [209 to 210].

Experiments have been done on $\mathrm{Mg}, \mathrm{Zn}, \mathrm{Fe}, \mathrm{Sb}$, Al oxides [211, 212] or tin slags [213], but the most extensively treated material is silica with the aim of preparing ultrafine silica powder (used at a rate of about $10000 \mathrm{t}$ per year) $[207,208,210,214,199]$. In all the cases the most important physical phenomena is condensation.
3.3.4 Condensation. - We will deal only with the condensation of the vapour to obtain very small particles. This vapour is obtained either from vaporisation of solid materials or by high temperature reaction between a reactant vapour $\left(\mathrm{SiCl}_{4}, \mathrm{TiCl}_{4}, \ldots\right)$ and the plasma $\left(\mathrm{O}_{2}, \mathrm{CH}_{4}, \mathrm{~N}_{2}\right)$ to get for example $\mathrm{SiO}_{2}, \mathrm{TiO}_{2}, \mathrm{TiC}, \mathrm{SiC}, \mathrm{TiN}, \mathrm{Si}_{3} \mathrm{~N}_{4}, \ldots[14,215,217]$. The controlling step of condensation is nucleation, which takes place when the vapour pressure exceeds the equilibrium vapour pressure of the condensed phase in the system. Often a certain degree of undercooling is necessary before nucleation occurs at a significant rate. The rate equation for nucleation is as follows :

$$
I=A \exp \left(-\frac{\Delta G_{\mathrm{c}}}{k T}\right)
$$

the non constant preexponential term, $A$, is dominated by $\Delta G_{\mathrm{c}}$ which depends sensitively on supersaturation $\rho / \rho_{0}$

$$
\Delta G_{\mathrm{c}} \sim \frac{\gamma^{3}}{\operatorname{Ln}\left(\rho / \rho_{0}\right)}
$$

where $\gamma$ is the interfacial energy. In plasma, nucleation occurs at a supersaturation of 2-3. The different studies specially on $\mathrm{SiO}_{2}$ and $\mathrm{TiO}_{2}[218,219]$ emphasize the rapidity of nucleation and the importance of coalescence for the final particle size. However condensation of silica is a special case because liquid silica is very viscous and crystallisation does not occur on cooling, the rate of coalescence may be estimated from equation developed for sintering by viscous flow [220]. From this theory coalescence to form spherical particles would be expected to cease at temperature below approximately $2200^{\circ} \mathrm{C}$. Condensation under this temperature, as is has been observed [208], result in the formation of chains of very small particles.

For the materials which condense to liquid droplets rather than solid particles it is possible to condense two or more components to give liquid solution droplets [221] $\left(\mathrm{Al}_{2} \mathrm{O}_{3}-\mathrm{SiO}_{2}, \mathrm{Al}_{3} \mathrm{O}_{4}-\mathrm{Cr}_{2} \mathrm{O}_{3}, \ldots\right)$.

At least the solidification of liquid droplets suspended in a cooling gas stream will be different of that observed under normal conditions because they will tend to undercool well below the equilibrium melting point before crystallisation. Due to the very high cooling rate $\left(10^{4}-10^{6} \mathrm{~K} / \mathrm{s}\right)$ both effects may result in the formation of metastable phases as discussed in detail by McPherson [221]. A number of studies have been made for $\mathrm{Al}_{2} \mathrm{O}_{3}, \mathrm{SiO}_{2}, \mathrm{TiO}_{2}$ and their mixture [ 222 to 226$]$.

3.4 CHEMICAL REACTIONS. - When the plasma A is inert and just used to decompose the product :

$$
\mathrm{A}+\mathrm{CD} \rightleftarrows \mathrm{C}+\mathrm{D}+\mathrm{A}_{(\mathrm{g})}
$$

the problems becomes essentially one heat transfer. 
When the plasma $\mathrm{A}$ is reactive with the condensed phase B :

$$
\mathrm{A}_{(\mathrm{g})}+\mathrm{B} \rightleftarrows \mathrm{C}+\mathrm{D}_{(\mathrm{g})}
$$

$C$ being condensed and $D_{(\mathrm{g})}$ a reaction gas, one has to compare the diffusion phenomena to the heat transfer phenomena (before diffusing, the vapour must be produced by heat transfer) Bonet [227] shows that the characteristic times $\mathrm{d} t_{\mathrm{D}}$ and $\mathrm{d} t_{\mathrm{T}}$ are such as :

$$
\frac{\mathrm{d} t_{\mathrm{D}}}{\mathrm{d} t_{\mathrm{T}}}=\frac{C_{\mathrm{p}}\left(T_{\mathrm{g}}-T_{\mathrm{p}}\right)}{\rho_{\mathrm{vs}} \Delta H_{\mathrm{T}}}
$$

where $C_{\mathrm{p}}$ is the specific heat of $\mathrm{B}, T_{\mathrm{g}}$ the plasma temperature, $T_{\mathrm{p}}$ the particle temperature, $\rho_{\mathrm{vs}}$ the mass concentration of the vapour at the particle surface and $\Delta H_{\mathrm{T}}$ the enthalpy flux (including the reaction enthalpy). Usually $\Delta H_{\mathrm{T}}>C_{\mathrm{p}}\left(T_{\mathrm{g}}-T_{\mathrm{p}}\right)$. So if $\rho_{\mathrm{vs}}$ is important then the decomposition process cannot be neglected for particle with $(\varphi<200 \mu \mathrm{m})$.

For example the molybdenium disulfide desulfurization process is controlled by heat transfer and $\mathrm{MoS}_{2}$ starto reacting appreciably in the solid state from $1773 \mathrm{~K}$ [228]. In flight (studies have been made with a FCC plasma) the moving particles go through the following phases :

1) $T_{\mathrm{p}}=1773 \mathrm{~K}:$ solid state (flake) : no reaction, only heating.

2) $1773 \mathrm{~K}<T_{\mathrm{p}}<1923 \mathrm{~K}$ : solid state : (i) heating of $\mathrm{MoS}_{2(1)}$; (ii) conversion of

$$
\mathrm{MoS}_{2(\mathrm{~s})} \rightarrow \mathrm{Mo}_{(\mathrm{s})}+\mathrm{S}_{2(\mathrm{v})}
$$

(iii) heating of $\mathrm{Mo}_{(\mathrm{s})}$.

3) $T_{\mathrm{p}}=1923 \mathrm{~K}$ : melting : (i) heat for melting of $\mathrm{MoS}_{2(\mathrm{~s})}$; (ii) conversion of $\mathrm{MoS}_{2(\mathrm{~s})} \rightarrow \mathrm{Mo}_{(\mathrm{s})}+\mathrm{S}_{2(\mathrm{v})}$ (converted Mo stays at $1923 \mathrm{~K}$ ).

4) $1923 \mathrm{~K}<T_{\mathrm{p}}<2892 \mathrm{~K}$ : solid liquid state : (i) conversion of $\mathrm{MoS}_{2(1)} \rightarrow \mathrm{Mo}_{(\mathrm{s})}+\mathrm{S}_{2(\mathrm{v})}$; (ii) heating of $\mathrm{MoS}_{2(1)}$; (iii) heating of $\mathrm{Mo}_{(\mathrm{s})}$ (continues still conversion takes place).

5) $T_{\mathrm{p}}=2892 \mathrm{~K}:$ melting $\mathrm{Mo}_{(\mathrm{s})} \rightarrow \mathrm{Mo}_{(\mathrm{l})}$.

6) $2892 \mathrm{~K}<T_{\mathrm{p}}<4919 \mathrm{~K}$ : heating of liquid Mo.

7) $T_{\mathrm{p}}=4919 \mathrm{~K}:$ vaporizing : $\mathrm{Mo}_{(1)} \rightarrow \mathrm{Mo}_{(\mathrm{v})}$; (Mo vapour causes loss in Mo recovery).

On the contrary for the reduction of $\mathrm{Fe}_{2} \mathrm{O}_{3}$ with hydrogen or carbon in plasma furnace [229] the process seems to be controlled by diffusion. The diffusion time for $60 \mu \mathrm{Fe}_{2} \mathrm{O}_{3}$ particles is high $(0.1 \mathrm{~s})$ and the main problem is to use a plasma device with a long residence time to allow the chemical reaction to proceed to a significant extent. Falling film furnaces are very well suited for this; they make use of a hollow cylindrical anode into which the particles are fed in a gas vortex, melting to form a liquid falling film on the anode wall. The melted film is heated by the plasma as in others configurations but is also heated by the Joule effect and electron condensation (anode) thus enhancing the efficiency of the heat transfer to the reactants and reducing the heat losses to the electrodes. The first furnace of this type was designed for MHD research [235] but the most efficient is that of Mac Rae figure 26 [236] used at a power level of $1 \mathrm{MW}$ for iron ore reduction and of $400 \mathrm{~kW}$ for ferrovanadium preparation [237].

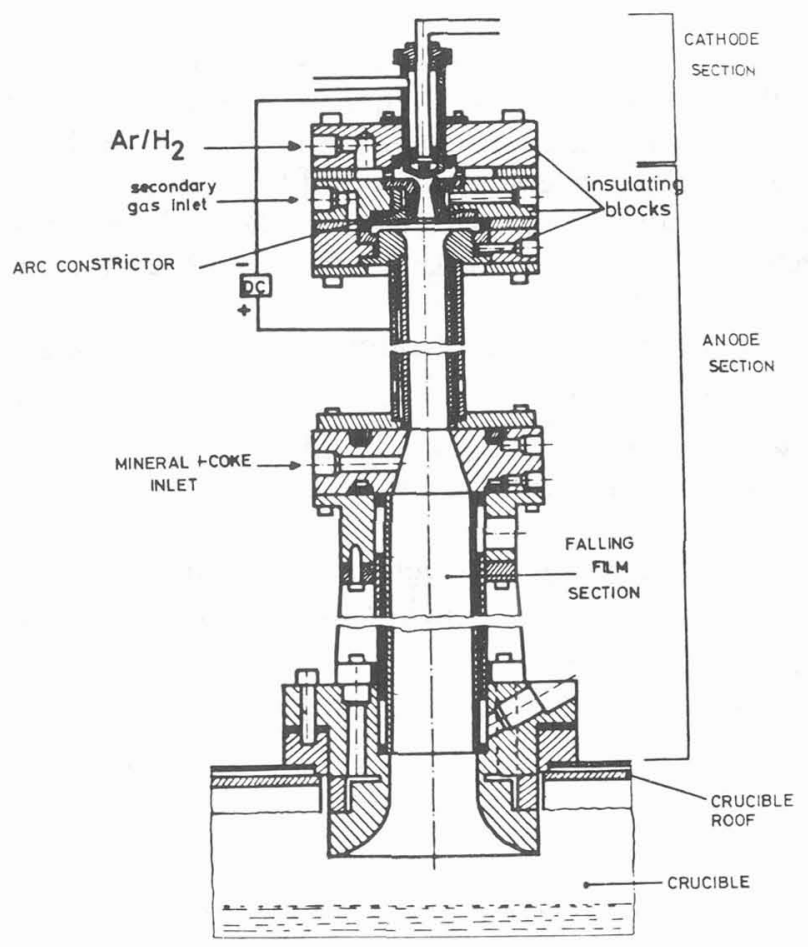

Fig. 26. - Bethlem Steel's $1 \mathrm{MW}$ falling film furnace (after US Pat 400246611 th Jan 1970).

Conclusion. - If plasma chemistry is known since the beginning of the century, a lot of experiments (some zoological description) has been made between 1955 and 1970. However important progresses have been achieved only in the seventies with the improvement of measurement techniques. This helped to identify, in homogeneous reactions, the role of the excited states and of the kinetic, electronic, vibrational and rotational excitation and to show that the most important part of plasma chemistry is the quenching of the excited new species formed. For heterogeneous reactions the improvement of the measurement techniques allows a better understanding of the heat and mass transfer phenomena between the plasma and the particles.

Among the diagnostic techniques used one has to emphazise the use of laser diagnostic, either to determine by fluorescence the rate coefficients of reactions with excited species specially the metastable ones that may allow specific stereochemistry or to study the particles velocity and diameter.

In the future as electricity becomes the most reliable and versatile source of energy, industrial uses 
of plasma chemical reactors will become increasingly attractive because :

1) they can be operated and stopped very quickly;

2) their energy density is very high and the reaction are very fast compared to the classical reactors allowing the use of small units with a rather low investement cost;

3) they are usually not polluting.

However, a lot of progress has yet to be made to further understand what happens during plasma treatment from a microscopic point of view in order to improve the conversion rates and the specific energy consumptions of the reactors. For example catalysis seems to be very promising but almost everything remains to be done.

The main areas of research in plasma chemistry seems now to be :

- research on reactions with excited states : stereochemistry with metastable states, eximers and flowing lasers...

- research on the destruction of polluting molecules $\left(\mathrm{SO}_{2}, \mathrm{NO}_{2}, \mathrm{NO} \ldots\right)$, high atmosphere and space chemistry...
- production of molecules with high added values either in organic chemistry or for ceramics with specific cristalline structure...

- production of molecules with low added values improving the conversion rates and energy consumption, in particular, due to the oil crisis, researches are developped for NO production from air, $\mathrm{C}_{2} \mathrm{H}_{2}$ and $\mathrm{C}_{2} \mathrm{H}_{4}$ from coal...

- extractive metallurgy by plasma allowing the local treatment of low grade ores and the production of high purity metals...

- production of submicronic powders or spheroidized particles for sintering...

- development of the plasma sprayed coatings for wear and corrosion protection, thermal and electrical barrier surfaces with low coefficients of friction...

- surface treatment in low pressure plasmas for electronic, optical and wear resistance applications...

Acknowledgments. - The authors are extremely grateful for the assistance given by Professor Boulos of the University of Sherbrook in preparing this lecture and for his fruitful comments.

\section{References}

[1] Edstrom, J. S., Petrochem. Industr. 2 (1904) 399.

[2] Baronnet, J. M., Contribution à l'étude spectroscopique des plasmas d'azote produits par un générateur à arc souffé; application de la chimie des plasmas : synthèse des oxydes d'azote, Thèse de Doctorat d'Etat, Université de Limoges (1978).

[3] Cappezuto, P. et al., J. Phys. Chem. 60 (1976) 882.

[4] Catherinot, A., SY, A., Z. Naturforch 30a (1975) 1143.

[5] Srouk, V. L., Eremin, E. N., Russ. J. Phys. Chem. 49(4) (1975) 917.

[6] Venugopalan, M., Plasma Chemistry. An introduction. In : Reactions under plasma conditions. Ch. XI. Vol. II (ed.) Venugopalan : Wiley Interscience N.Y. (1971).

[7] Muller, K. G., Non equilibrium plasmas and their diagnostics, invited paper of the Third International Symposium on Plasma Chemistry, Limoges July 13-19 1977.

[8] LleWEllyn-JoNEs, F., The glow discharge (Ed.) : Methuen London (1966).

[9] Davimson, R. C., I.E.E.E., I.A.S. Conference on applied electrostatics, Toronto (1978).

[10] Thomas KITZe, P, CARLey, J. F., R.G.C.P. 52 (1975) 463.

[11] Hirsh, M., Décharges HF et microondes, Séminaire Chimie des Plasmas, Dourdan 20-24/02/78 (ed.) A.D.E.R.P. Orsay.

[12] Feusenfeld, F. C., Evenson, K. M., Brotda, H. P., Rev. Sci. Instrum. 36 (1955) 294.

[13] Hubert, J., Moisan, M., RiCard, A., Spectrochimica Acta 33 (1979) 1.

[14] Rykalin, N. N., Pure and Appl. Chem. 48 (1976) 179.

[15] Mackinnon, I. M., Reuben, B. G., J. Electrochem. Soc. 122 (1975) 806

[16] Roman, W. C., ZaBIelski, M. F., Spectroscopic Gas Composition Measurement of $U F_{6} R F$ plasmas. Presented at 30th Annual Gaseous Electronics Conference, Palo Alto, CA, oct. (1977).
[17] Gage, R. M., Arc Torches and process, U.S. Patent 2 (1957) $806,124$.

[18] Bose, T. K., Pfender, E., A.I.A.A. Journal 7 (1969) 1643.

[19] Shim, K. T., Pfender, E., A.I.A.A. Journal 8 (1970) 211.

[20] Cambray, P., Contribution à la mesure des flux de chaleur et de la vitesse d'écoulement du plasma dans un générateur $\grave{a}$ arc soufflé, Thèse de $3^{\mathrm{e}}$ cycle, Université de Poitiers, 6 avril 1971.

[21] Hassan, H. A., Smith, N. S., A.I.A.A. Journal 8 (1970) 657.

[22] Leontiev, A. J., Voltchkov, E. P., Caractéristiques électriques et thermiques d'un plasmatron de haute enthalpie in Investigations expérimentales des plasmatrons, M. F. Joukov. Ed. Nauka Novossibirk (1977).

[23] KImBLIN, S. U., Erosion des électrodes et processus d'ionisation entre les électrodes de l'arc dans le vide et à la pression atmosphérique, p. 226 in Investigations expérimentales des plasmatrons, MF Joukov ed. Nauka Novissibirk (1977).

[24] Romalo, D. I., Revue Roumaine des Sciences et Techniques, Série électrotechnique et énergétique 13 (1968) 415.

[25] Finkelnburg, W., MAECKer, N., Elektrische Bogen und thermiches Plasmas Handbuch der Physik, SpringerVerlag, Berlin (1956).

[26] Nachman, M., Rev. Hies Temp. et Réfract. 10 (1973) 65.

[27] Prender, E., Electric Arcs and Arc Gas Heaters, in Gaseous electronic (ed.), M. N. Hirsh, H. J. Oskam, Acad. Press (1978).

[28] Hoyaux, M. F., Arc Physics (Applied Physics and Engineering, vol. 8) Springer Verlag, Berlin (1968).

[29] BouRdiN, E., Calcul approximatif d'une tuyère de torche à plasma par application du modèle à propriétés constantes, Rap. Int. Lab. Thermodynamique, avril 1978.

[30] Schoumaker, H. R. P., Fours à chauffage plasma, in Conference Proceedings of International Round Table on Study and Application of Transport Phenomena in Thermal Plasma, Odeillo, sept. 1975. 
[31] Gememan, W. A. Vr, A general discussion of plasma generator design consideration and operating characteristics, Plasmadyne Corporation, PRE 107.

[32] Sсновск, P. A., Ph. D. Thesis Univ. Minnesota (1961)

[33] Joukov, M. F., Koroteel, OurioukoB, B. A., Hydrodynamique appliquée des plasmas thermiques. Rédacteur : Koutatrieladze S. S. Ed. Nauka, Novossibirsk (1975).

[34] Joukov, M. F., KourotchKine, Poustogarov, A. V., Etude des plasmatrons utilisant des gaz plasmagènes soufflés à travers un étage rapporté entre les électrodes, p. 82 in Investigation expérimentale des plasmatrons, MF Joukov Ed. Nauka, Novossibirk (1977).

[35] Schnell, C. R., Hamblyn, S. M. L., Hengartner, K. and WissLer, M. (Lonza Ltd), The industrial application of plasma technology for the production of fumed silica, presented at the Symposium Commercial Potential for Arc and Plasma Processes, Atlantic City, N.J., 8-11 septembre 1974

[36] Fey, M. G., Kemeny, G. A., Method of direct ore reduction using a short gap arc heater, U.S. patent 3, 16 oct. 1973, 765,870 .

[37] Bonet, C. and al., J. Phys. D., Appl. Phys. 9 (1976) L 141.

[38] Shakov, M. F., Smolyakov, V. Ya., URGukov, B. A., Electric-Arc Heaters of Gases (ed.) Nauka, Moscow (1973).

[39] Grimaud, A., Thèse 3e cycle, U.E.R. des Sciences, Limoges (1973).

[40] Gladish, H., Hydrocarbon. Process. Petrol. Refiner 41 (1962) 159

[41] StOKes, C. S., KNIPE, W. W. et STRENG, J. Electrochem. Soc. 107 (1960) 35.

[42] Korman, S., Inter. Sci. Tech. 30 (1964) 90.

[43] Gibson, J. O., Wamman, R., Chem. Ing. Progr. 9 (1963) 53.

[44] Holmgren, J. D., Gibson, J. O., SHeER, C., J. Electrochem. Soc. 111 (1964) 362

[45] Kelly, A. J., J. Chem. Phys. 45 (1966) 1723.

[46] Maecker, H., Z. Physik 136 (1953) 119.

[47] Marinowski, G. W., Phillips, R. C., Phillips, T. R., HIESTER, N. K., Ind. Eng. Chem. Fundamentals 1 (1962) 52.

[48] Meubus, P., J. Electrochem. 122 (1975) 298.

[49] Baddour, R. F., Blanchet, J. L., Ind. Ing. Chem. Process. Design. Develop. 3 (1964) 258

[50] Timmins, R. S. et Amman, P. R., A.I. Ch. E.J. 12 (1966) 956.

[51] Anderson, J. E., Case, L. K., Ind. Eng. Chem. Process. Design. Develop. 1 (1962) 161.

[52] Stokes, C. S., Streng, L. A., Ind. Eng. Chem. Process. Design. Dev. 4 (1965) 36.

[53] Gladish, H., Hydrocarbon. Process. Petrol. Refiner 41 (1962) 159.

[54] GREY, J., JACOBS, P. R., A.I.A.A. : J. 2 (1964) 433.

[55] PoLAK, L., Some principles of non equilibrium plasma chemical reaction kinetics, ch. 13, p. 141, T. 2, Plasma Chemistry Ed. Venugopalan, Wiley-Interscience, N.Y. (1971).

[56] Kaufman, F., Kelso, J. R., J. Chem. Phys. 32 (1960) 301.

[57] Young, R. A., Sharpless, R. L., Sringham, R., J. Chem. Phys. 40(1) (1964) 117.

[58] Safrany, Harteck, Reevgs, J. Chem. Phys. 41 (1964) 1161.

[59] Baker, R. R., Jakob, A., Winkler, C. A., Can. J. Chem. 49(2) (1971) 1671 .

[60] Brookes, B. W., Seaport, R. M., J. Appl. Chem. Biotechnol. 24 (1974) 621.

[61] Eremin, E. N., Syaduk, V. L., Russ. J. Phys. Chem. 49(4) (1975) 587.

[62] Eremin, E. N., Bebeshro, Russ. J. Phys. Chem. 48(1) (1974) 50

[63] Eremin, E. N., Russ. J. Phys. Chem. 48(8) (1974) 1229.

[64] Eremin, E. N., Russ. J. Phys. Chem. 48(8) (1974) 1256.

[65] Eremin, E. N., Syaduk, V. L., Russ. J. Phys. Chem. 47(6) (1973) 864.

[66] Eremin, E: N., Rubatsova, Russ. J. Phys. Chem. 47(1) (1973) 35.
[67] Eremin, E. N., Syaduk, V. L., Russ. J. Phys. Chem. 46(11) (1972) 1644.

[68] Rapakoulias, D., Etude des processus de fixation de l'azote dans un réacteur chimique à plasma hors équilibre. Mise en évidence de processus catalytique, Thèse de Doctorat ès Sciences Physiques, Université de Paris VI, 11/06/1979.

[69] Cavadias, S., Synthèse directe des oxydes d'azote dans un réacteur à plasma basse pression hors équilibre, Thèse de $3^{\text {e }}$ cycle, Université de Paris VI, 11/06/1979.

[70] Griem, H. R., Plasma Spectroscopy (ed.) Mc Graw-Hill, N.Y. (1964)

[71] Drawin, H. W., High Pressures, High Temperatures 2 (1970) 359.

[72] Ranson, P., Chapelle, J., J.Q.S.R.T. 14 (1974) 1.

[73] Ranson, P., Thèse de Doctorat d'Etat, Université d'Orléans (1978).

[74] Catherinot, A., Sy, A., Z. Naturforsch. 30a (1975) 1143.

[75] Delcroix, J. L., Physique des Plasmas (ed.) Dunod, Paris (1963).

[76] Drawin, H. W., Reactions under plasma conditions (ed.) Venugopalan, M., Wiley Interscience, N.Y. (1971).

[77] Stupochenko, Y. V., Losev, S. A., Osupov, A. J., Relaxation in shock waves, International series applied physics and engineering, 1 (ed.) Springer Verlag (1967).

[78] Leskov, L. V., Savin, F. A., Soviet Physics Uspekhi 3 (1961) 912.

[79] Losev, S. A., OsIrov, A. L., Soviet Physics Uspekhi 74 (1962) 525 .

[80] ZeLDOvich, B., RaISER, Y., Physics of shock waves and high temperature hydrodynamic phenomena (ed.) Academic Press N.Y. (1966).

[81] RowE, B., Etude des réactions chimiques et ioniques dans un plasma en fort déséquilibre thermodynamique. Cas du mélange azote-argon, Thèse de doctorat d'Etat, Université de Paris VI (1975).

[82] Cabannes, F., Molecular Spectroscopic Diagnostics, in Analytical Uses of Plasmas (ed.) R. M. Barnes, John Wiley N.Y. (1978).

[83] Bourasseau, D., Contribution à l'étude de l'équilibre thermodynamique local dans les jets de plasma d'argon sous pression réduite, Thèse de doctorat de $3^{\mathrm{e}}$ cycle, Paris (1968).

[84] First report on spectroscopic methods of temperature measurements, IUPAC, report of the committee on standards and measurements in plasma chemistry (ed.) P. Fauchais, Limoges University (1979).

[85] Bayard, S., Contribution au calcul des fonctions de partition des plasmas azote-silicium-aluminium et détermination des températures à partir du fond continu de l'azote. Thèse de $3^{\mathrm{e}}$ cycle, Université de Limoges (1974).

[86] HoFSAESS, D., J.Q.S.R.T. 19 (1978) 339.

[87] Figffe-Prevot, P., Rev. de Physique Appliquée 12 (1977) 1243.

[88] Olsen, H. N., Bedtai, G., Kelly, F. L., Development of diagnostic methods for seeded air and nitrogen plasma, A.E.D.C.-T.R.-68-217.

[89] Ranson, P., Chapelle, J., J.Q.S.R.T. 14 (1974) 1.

[90] Konjevic, J., J. Phys. Chem. Ref. Data 5 (1976) 209.

[91] CouderT, J. F., Contribution à l'étude de la synthèse des oxydes d'azote par chalumeau à plasma, Thèse de $3^{\mathrm{e}}$ cycle, Université de Limoges (1978).

[92] Catherinot, A., SY, A., Quenching of the $3 p^{4} S$ atomic nitrogen state in a low pressure nitrogen glow discharge, Phys. Rev. A (à paraître).

[93] Dubreull, B., Catherinot, A., Physica 93C (1978) 408.

[94] Dubreull, B., Catherinot, A., J. Phys. D 11 (1978) 1043.

[95] Catherinot, A., Placidet, P., Dubreuil, B., J, Phys. B 11 (1978) 3775

[96] Catherinot, A., Dubreuil, B., Gand, M., Phys. Rev. A 18 (1978) 1097.

[97] Dubreuil, B., Catherinot, A., J. de Phys. 39 (1978) 1071.

[98] Fiszdon, J., Gauk, Daniaul, Rev. Int. Htes Temp. et Réfract. 13 (1976) 11. 
[99] HARE, A. L., Velocity measurements in plasma flows using cooled pitot tubes : an unsolved problem, Proceedings G.3.9., IIId International Symposium on Plasma Chemistry, Limoges (1977).

[100] Fiszdon, J., Lesinski, J., International Round Table on Study and Application of Transports Phenomena in Thermal Plasmas, Odeillo 12-16 sept. 1975.

[101] Cambray, P., Contribution à la mesure des fux de chaleur et de la vitesse d'écoulement du plasma dans un générateur $a ̀$ arc soufflé, Thèse de $3^{e}$ cycle, Poitiers (1971).

[102] Guyonnet, J., Borie, A., Faucrais, P., Projection au chalumeau à plasma de revêtements céramiques à coefficients de frottement variables, in Proceedings IV-5 of International Round Table on Study and Application of Transport Phenomena in Thermal Plasmas, I.U.P.A.C., Odeillo, 12-16 sept. 1975.

[103] Gouesbet, G., Phénomènes de diffusion et de thermodiffusion des espèces neutres dans un plasma d'argon et d'hélium, Thèse de Doctorat d'Etat, Université de Rouen (1977).

[104] VARDELle, A., Contribution à la mesure statistique des vitesses et des températures de surface de particules injectées dans un jet de plasma d'arc, Thèse de $3^{\mathrm{e}}$ cycle, Université de Limoges (1979).

[105] Lesinski, J., Lesinska, B., Fanton, J. C., Boulos, M. I., L.D.A. Measurements under plasma conditions, 4 th International Sympositum on Plasma Chemistry, Zurich, August 27. Sept. 1st, 1979.

[106] Cambray, P., Mesure de vitesse dans des jets de plasma comportant des gradients axiaux, Proceedings G.3.2., $3 d$ International Symposium on Plasma Chemistry, Limoges University (1977).

[107] LerGoN, H. G., MÜLlER, K. G., Verhandlung der Deutschen Physikalischen Gesellschaft, 1977, p. 699.

[108] Perugrni, G., Analysis of dynamic fusion phenomena of ceramic and metallic powders injected into an argon plasma jet, $3 d$ International Meeting on Modern Ceramics Technologies, Rimini, Italy (1976).

[109] Todorovic, P. S. et al., Spectrochimica Acta 313 (1976) 103.

[110] ANDRÉ, M., Les techniques de cinématographie ultra-rapide, C.E.A., Centre de Limeil, France (1977).

[111] Gold, D., J. of Physics $E$ : Scientific Instruments 10 (1977) 395.

[112] DURST, F., ZARE, M., Bibliography of laser doppler anemometry litterature, University of Karlsruhe, published by DISA Information Department.

[113] BoutIER, A., Data processing in laser anemometry 3d Internation workshop on laser velocimetry, Institut FrancoAllemand de Saint-Louis France (1976).

[114] Edwards, R. V. et al., J. Appl. Phys. 42 (1971) 837.

[115] Edwards, R. V. et al., J. Appl. Phys. 44 (1973) 1694.

[116] Caspersen, C., Saustrap, H., Kristensen, L.D.A. Measurements in a low-velocity wind tunnel on a thin plate model DISA information 17 (1975).

[117] SeLF, S. A., Laser doppler velocimetry in MHD boundary layer. Eng. Aspects Magnet. 14th Symp. Tullahoma Tenn. (1974).

[118] STEENSTRUP, F. V., DISA Information 18 (1975) 21.

[119] ABBiss, J. B., Seminar given at NATO advanced study, institute on photon correlation spectroscopy and velocimetry, Capr1 (Italy), 26 july, 6 august 1976

[120] BONET, C., Description d'une méthode de mesure de la température d'une particule en mouvement, Réunion R.C.I' Gaz Ionisés Réactifs, Paris le 10/02/1978 (ed.) P. Fauchais, Limoges University.

[121] Kruszewska, B., Lesnski, J., Rev. Phys. Appliquée 12 (1977) 1209.

[122] Penner, S. S., Chang, P., J.Q.S.R.T. 20 (1978) 447.

[123] Barrere, M., Prud'homme, R., Equations fondamentales de l'aérothermochimie, Masson et Cie éditeurs, Paris (1973).

[124] Zeleznick, F. J., GoRdon, S., Industrial Engineering Chemistry 60 (1968) 6.
[125] STOREY, S. H., VAN ZEGEREN, F., The computation of chemical equilibria, Cambridge University Press (1970).

[126] Bourdin, E., Contribution à l'étude théorique et expérimentale de la synthèse de nitrures par réaction d'un jet de plasma d'azote avec des poudres d'aluminium et de silicium, Thèse de $3^{\text {e }}$ Cycle, Université de Limoges (1976).

[127] Fauchais, P., Baronnet, J. M., Bayard, S., Rev. Int. Hies Temp. et Réfract. 12 (1975) 221.

[128] Coldwell, D. M., High Temperature Science 8 (1976) 309

[129] FranK-KamenESTKII, D., Diffusion and heat transfert in chemical kinetics, Plenum Press, New York-London (1969).

[130] WARner, D. D., The Journal of Physical Chemistry 87 (1977) 2329.

[131] Emanuel, N., K NorRe, D., Cinétique chimique, Edition Mit. Moscou (1975).

[132] JoHston, H., Gas phase reaction rate theory, Ronald Press company. New York (1966).

[133] Gladstone, S., Lamier, J. K., Eyring, H., The theory of rate processes, Mc Graw-Hill Book Company, Inc. New York and London (1941)

[134] Cacciatore, M., Capiteldi, M., Z. Naturforsch. 30a (1975) 48.

[135] Cacclatore, M., Capitelli, M., Z. Naturforsch. 31 a (1976) 362.

[136] Baronnet, J. M. et al., Journal de Chimie Physique 75 (1978) 949.

[137] Baronnet, J. M., Coudert, J. F., Rakowitz, J., Bourdin, E., Fauchays, P., Nitrogen oxides synthesis in a DC plasma jet, 4th Internation. Symposium on Plasma Chemistry, Zurich, august 27, sept. 1st, 1979.

[138] Prud'homme, R. et al., Rapport ONERA, Paris (1969).

[139] Baulch, D. L., High Temperature Reaction Rate Data, $\mathrm{n}^{\circ} 4$, Leeds (1969).

[140] Polanyi, J. C., Chem. Phys. 5(5) (1972) 161.

[141] Badger, R. M. et al., J. Chem. Phys. 43 (1965) 4345.

[142] Foner, S. N., Hudson, R. L., J. Chem. Phys. 25 (1956) 601.

[143] Arnold, S. J., Dyryzlo, E. A., Witzke, H., J. Chem. Phys. 40 (1964) 1769.

[145] Dumas, J. L., Garnier, B., Journal de Chimie Physique 9 (1975) 1045 .

[146] Clyne, M., Thrush, B., Wayne, R., Photochem. Photob. 4 (1965) 957.

[147] Dumas, J. L., Bulletin de la Société Chimique de France 5-6 (1976) 658.

[148] Dumas, J. L.; Bulletin de la Société Chimique de France 5-6 (1976) 661

[149] Dumas, J. L., Bulletin de la Société Chimique de France 5-6 (1976) 665.

[150] Bourdin, E., Aubreton, J., Fauchais, P., Equilibrium composition and thermodynamic properties of $\mathrm{C}-\mathrm{H}_{2}$, $\mathrm{CH}_{4}$ and $\mathrm{CH}_{4}-\mathrm{H}_{2}$ plasmas, computation of their reducing action on iron oxyde $\mathrm{Fe}_{2} \mathrm{O}_{3}$. In : IIIrd International Symposium on plasma Chemistry, Limoges July (1977); Proceedings III-G4-2.

[151] Devoto, R. S., Phys. of Fluids 10 (1967) 2105.

[152] Mason, E. A., Kinetic processes in gases and plasma (ed.) A. R. Hochstim Academic Press, N.Y. and London (1969).

[153] Chapman, S., Cowling, T. G., The mathematical theory of non uniform gases (ed.) Cambridge University Press, U.K. (1970).

[154] ATHYE, W. F., A critical evaluation of methods for calculating transport coefficients of partially and fully ionized gases, NASA TN, ND-2611 (1965).

[155] Devoto, R. S., Phys. of Fluids 9 (1966) 1230.

[156] Devoto, R. S., Li, C. P., J. Plasma Physics 2 (1968) 17.

[156] Devoto, R. S., A.l.A.A. Journal 7 (1969) 2.

[157] Devoto, R. S., Phys. of Fluids 16 (1973) 616

[158] Devoto, R. S., Capitelli, M., Phys. Fluids 16 (1973) 1835. 
[159] Butler, J. N., BRokaw, R. S., Journal of Chemical Physics 26 (1957) 1636.

[160] Vanderslice, J. T., Weisman, S., Moson, E. A., Fallon, R. J., Phys. of Fluids 5 (1962) 155.

[161] GoRse, C., Contribution au calcul des propriétés de transport des plasmas des mélanges argon-hydrogène et argon-azote. Thèse de $3^{\mathrm{e}}$ cycle, Université de Limoges, 9 septembre 1975.

[162] PeTrIe, I. W., The effect of ionization on heat transfert to wires immersed in an arc plasma. Ph. D. Thesis University of Minnesota (1969).

[163] Pfender, E., Pure and Appl. Chem. 48 (1976) 199, Pergamon Press.

[164] Finkelnburg, W., Maecker, H., Elektrische Bögen und Thermisches Plasma. Encyclopedia of Physics (ed. S. Flügge), vol. 22, p. 254, Springer, Berlin (1956).

[165] ECKER, G., Electrode components of the arc discharge Ergebnisse d. exakten naturwiss., vol. 33, p. 1, Springer, Berlin (1961).

[166] Kimbuin, C. W., Anode phenomena in vacuum and atmospheric pressure arcs, I.E.E.E. Trans. plasma Sci., PS-2 (4), 310 (1974).

[167] Boulos, M. A., Gauvin, W. H., Can. J. Chem. Eng. 52 (1974) 355.

[168] Bhattacharyya, D., Gauvin, W. H., A.I.Ch.E. 21 (1975) 879.

[169] Lewis, J. A., Gauvin, W. H., A.I.Ch.E.J. 19 (1973) 982.

[170] Boulos, M. A., III Symposium International de Chimie des Plasmas : I.U.P.A.C.-S-3-2, Limoges (1977).

[171] Torobin, L. B., Gauvin, W. H., Can. J. Chem. Eng. 37 (1959) 129.

[172] Borgianni, C., Capitelli, M., Cramarossa, F., Triolo, L., Molinari, E., Combust. Flame 13, 2 (1969) 181.

[173] Yoshida, T., AKashI, K., Journal of Applied Physics, 48 (1977) 2252

[174] Rykalin, N. N., Kudinov, V. V., Pure and Appl. Chem. 48 (1976) 229.

[175] Besson, J. L., Boch, P., Plasma Spraying of Ceramics, International Round Table Discussion on Special Ceramics for Electronics and Electrical Engineering, Warsaw 8-11 oct. 1978.

[176] Ingham, H. S., ShePard, A. D., Metco Flame Spray Handbook (1965).

[177] Guyonnet, J., Brevet C.N.R.S. 124111 et additifs 168044 et 7044678 .

[178] Madejski, J., Int. J. Heat and Mass Transfer 19 (1976) 1009.

[179] Madejski, J., Bull. Acad. Pol. des Sciences 24, $\mathrm{n}^{\circ} 1$ (1976).

[180] Zoltowski, P., Rev. Int. Htes Temp. et Réfract. 6 (1968) 65.

[181] MeYer, Von H., Ber. Dtsch. Keram. Ges. 41 (1964) 112.

[182] Jones, H., Rep. Prog. Phys. 36 (1973) 1425.

[183] Donovan. M., Vrit. Weld. J. 13 (1966) 490.

[184] Kudinov, V. V., Kitaev, F. I., Tsidulko, A. G., Parosh, Metall. 152 (1975) 38.

[185] MCPherson, R., J. Mats. Sci. 8 (1973) 851.

[186] Sokolova, T. V., Kozlova, I. R., Derko, Kh. Kirko, A. V., Izv. Akad. Nauk. S.S.S.R., Neorg. Mat. 9 (1973) 611.

[187] EICHORN, F., METZLER, J., EYSEL, W., Metalloberflaeche 26 (1972) 212 .

[188] Huffachine, J. B., Thomas, A. G., Powder. Met. 7 (1964) 290

[189] Thompson, V. S., Whittemore, O. J., Ceram. Bull. 47 (1968) 637.

[190] Guyonnet, J., Borie, A., Fauchais, P., Projection au chalumeau à plasma de revêtements céramiques à coefficients de frottement variables. In proceedings of the International Round Table on Study and Applications of Transport Phenomena in Thermal Plasmas, Odeillo 12-16 sept. 1975.

[191] Hamblyn, S. M. L., A review of application of plasma technology with particular reference to ferro-alloy production. National institute for Metallurgy Report no 1895, Randburg, South Africa, 14 April 1977.

[192] WaLDIE, B., Chem. Eng., Lond. 262 (1972) 188.

[193] Anon, Chem. Eng. 24 (1975) 56.
[194] Bonet, C., Vallbona, G., Foex, M., Bull. Soc. Franc. Ceramique 94 (1972) 27.

[195] Gani, M. S. J., MCPherson, R., J. Aust. Ceram. Soc. (in press).

[196] Wilks, P. H. et al., Chem. Eng. Prog. 68 (1972) 82.

[197] Sheer, C., Korman, S., KaNG, S. F., Investigation of convective arcs for the simulation of re-entry aerodynamic heating, AFORS-TR-74-1505, Contrat F-44 620-69-C-0104 (1974).

[198] Bayliss, R. K., Bryant, J. W., Sayce, I. G., Plasma dissociation of zircon sands, in the proceedings (S-5-2) of the III International Symposium on Plasma Chemistry, Limoges, France, 12-19 july 1977.

[199] Bonet, C., Vallbona, G., Foex, M., Daguenet, M., DumarGUE, P., Rev. Int. Htes Temp. et Réfract. 11 (1974) 11.

[200] Maecker, H., Z. Physik 136 (1953) 119.

[201] Pateyron, B., Interaction entre phénomènes de transport et processus de métallurgie par plasma, Rapport Interne laboratoire de Thermodynamique de l'Université de Limoges, juin 1978

[202] Bhattacharya, D., Gauvin, W. H., J. Appl. Phys. 47 (1976) 4863.

[203] Borgianni, C., Capitelli, M., Cramarossa, F., Triolo, L., MOLINARI, E, Combustion and Flame 13 (1969) 181.

[204] Johnston, P. D., Combust. Flame 18 (1972) 373.

[205] Bonet, C., Daguener, M., Dumargue, P., Int. J. Heat. Mass Transfer 17 (1974) 643

[206] Dong Hi Lee, McPherson, R., Proc. 9st Aust. Ceramics, conf. Melbourne (1978).

[207] SAyce, I. G., Selton, B., Special Ceramics. British Ceramics Research Association 5 (1972) 157.

[208] SAYCe, I. G., Pure and Appl. Chem. 48 (1976) 215

[209] Barnes, W. R., U.K. Patent 1 (1970) 211, 702.

[210] Korman, S., SHEER, C., Electrochem. Soc. Symp., Philadelphia (1966).

[211] SHEER, C. et al., Arc Vaporization of refractory powders, Proceedings of the Fine Particles Symposium, oct. 1973. Electrochem. Soc., Boston (Mass.).

[212] HowIE, F. H., SAYCE, I. G., Rev. Int. Htes Temp. et Réfract. 11 (1974) 169.

[213] Barrett, M. F., Howte, F. H., SAyce, I. G., Trans. Inst. Min. Metall. 84 (1975) C 231.

[214] Bonet, C., Vallbona, G., Foex, M., Bull. Soc. Fr. Ceram. 94 (1972) 27.

[215] ARkless, K., Ceaver, D., Vrit. Patent, 1226082 (1966).

[216] De Pous, O., Proc. 3rd Intl. Symp. Plasma Chem., IUPAC Université de Limoges (ed.) P. Fauchais, paper S-4.7 july 1977.

[217] Audsley, A., Bayliss, R. K., J. Appl. Chem. 19 (1969) 33

[218] UlRich, G., Combust. Sci. and Technol. 4 (1971) 47.

[219] Cozzi, C., Cadorin, D., Combust. Sc. and Tech. 5 (1972) 213.

[220] Mackenzie, J. K., Shuttleworth, R., Proc. phys. Soc. B 62 (1949) 833.

[221] McPherson, R.; Proc. Intl. Round Table Study Application of Transport Phenomena in Thermal Plasmas (ed.) C. Bonet IUPAC/CNRS Odeillo (1975).

[222] Holmgren, J. D., Gibson, J. O., Sheer, C., Ultrafine Particles (ed.) W. E. Kahn, Wiley, New York (1963).

[223] MCPHERSon, R., J. Mats. Sc. 8 (1973) 859.

[224] Dong Hi Lee, MCPherson, R., J. Mats. Sc. (in press).

[225] McPherson, R., J. Amer. Cer. Soc. (in press).

[226] Dong Hi Lee, McPherson, R., Proc. 3rd Intl. Symp. Plasma Chem., IUPAC/Université de Limoges (ed.) P. Fauchais, paper S-4-10, july 1977.

[227] Bonkt, C., Thermal Plasma Processing, Chemical Eng. Prog. USA 72, 12 (1976) 63.

[228] Munz, R. J., The decomposition of Molybdenium Disulphide in an induction plasma tail flame, $\mathrm{Ph}$. D. dissertation, Mc Gill Univ. (1974).

[229] Sieder, E. N., Tate, G. E., Ind. Eng. Chem. 28 (1936) 14291435. 
[230] Drrtus, F. W., Boelter, L. M. K., University Calif. Pub. Eng. 2 (1930) 443.

[231] Martinelli, R. C., Trans. ASME 69 (1947) 947.

[232] Ostrach, S., Nat. adv. comm. aeron., Tech. note 2665, Washington DC (1952).

[233] JAKOB, M., Dow, W. M., Trans. ASME 68 (1946) 124.

[234] HuANG, G. C., I. - Heat Transfer 85 (1963) 235.

[235] M.H.D. Research inc., U.K. Pat. 1 (1970) 205, 676.
[236] Gold, R. G., SANdall, W. R., Cheplick, P. G., Mac RaE, D. R., Plasma reduction of iron oxide with hydrogen and natural gas at $100 \mathrm{~kW}$ and $1 \mathrm{MW}$, International Round Table on Study and Application of Transport Phenomena in Thermal Plasmas, IUPAC Odeillo 12-16 sept. 1975.

[237] MAC RAE, D. R. et al., Ferrovanadium production by plasma carbothermic reduction of vanadium oxide, T. III, Third International Symposium on Plasma Chemistry, IUPAC Limoges, 13-19 juillet 1977. 